\title{
Burning Plasmas
}

H.P. Furth, R.J. Goldston, and S. J. Zweben

PPPL- -2722

Princeton Plasma Physics Laboratory

DE9 I 000506

\section{D.J. Sigmar}

Massachusetts Institute of Technology

\begin{abstract}
The fraction of fusion-reaction energy that is released in energetic charged ions, such as the alpha particles of the D-T reaction, can be thermalized within the reacting plasma and used to maintain its temperature. This mechanism facilitates the achievement of very high energy-multiplication factors $Q$, but also raises a number of new issues of confinement physics. To ensure satisfactory reactor operation, three areas of energetic-ion interaction need to be addressed: (1) single-ion transport in imperfectly symmetric magnetic fields or turbulent background plasmas; (2) energeticion-driven (or stabilized) collective phenomena; and (3) fusion-heat-driven collective phenomena. The first of these topics is already being explored in a number of tokamak experiments, and the second will begin to be addressed in the D-T-burning phase of TFTR and JET. Exploration of the third topic calls for high-Q operation, which is a goal of proposed nextgeneration plasma-burning projects. Planning for future experiments must take into consideration the full range of plasma-physics and engineering R\&D areas that need to be addressed on the way to a fusion power demonstration.
\end{abstract}

[To be published in Nuclear Fusion's 30th Anniversary' Issue, 1990] 


\section{Introduction}

If all the energy of fusion reactions were released in neutrons, the plasma-physics and nuclear-physics aspects of fusion research would be almost entirely decoupled. ${ }^{*}$ In that case, there would be some logic in pursuing an experimental program where hydrogen and deuterium plasmas are used to demonstrate a perfect plasma prototype for a D-T reacior, before the phase of D-T burning and reactor-technology development is undertaken. The plasma effects caused by the alphaparticles of the D-T reaction $1-3$ are, however, potentially very important: The $20 \%$ of the D-T fusion power that goes into the alpha-particles can take over the plasma-heating function (i.e., can "ignite" the plasma) when the fusion power equals five times the rate of plasma heat loss -- while introducing new problems of thermal instability. The pressure of the alpha-particle minority population can also excite new types of collective modes -- or help stabilize familiar ones.

Taking advantage of the favorable aspects of alpha-particle production, while learning to control the unfavorable ones, must clearly be a key element of any program to optimize fusion-reactor performance. The individual alpha-particle effects could all be simulated to some extent in non-D-T plasmas by means of neutral-beam-injected or rf-accelerated energetic-ion minorities, but high-confidence demonstration of a reactorplasma prototype will call for a genuine D-T-burning experiment. A parallel motivation for the timely start of experimental research on

\footnotetext{
"Except for the slow accumulation of helium ash, 4,5 which could be studied in non-burning plasmas by injecting helium directly.
} 
reactor-level D-T plasmas is to provide a sufficiently powerful source of energetic neutrons to support $R \& D$ efforts on fusion-reactor technology tasks, such as the development of reactor blankets, shielding, tritiumhandling systems, burning-plasma diagnostics, and remote-maintenance techniques.

The following sections of this chapter provide brief reviews of the fusion reactions of principal practical interest, the production of energeticion minority populations, the transport rates and collective bulk-plasma interactions of the energetic ions, the role of fusion-heat-driven collective phenomena, and the outlook for next-generation D-T-burning-plasma experiments. The discussion is focussed on D-T-burning in tokamak geometry, since this is the principal near-term prospect in magnetic fusion research. Burning-plasma experiments in the inertial-confinement area are discussed as part of a separate chapter.

\section{Fusion Reactions}

The fusion reactions of principal practical interest are shown in Table 1. The D-T reaction is strongly favored in present-day fusionreactor designs, 6-8 because the desired operating range in the Lawson diagram is most readily accessible (Fig. 1), and because D-T fuel gives the highest fusion-power density (Fig. 2). Accordingly, the discussion of energetic-ion phenomena in the following sections will focus principally on the $3.5-\mathrm{MeV}$ alpha-particles of the $\mathrm{D}-\mathrm{T}$ reaction. The use of pure deuterium fuel would have the advantage of eliminating the need for a tritium breeding blanket and the associated large tritium inventory, but would not be helpful in reducing problems related to neutron emission: As 
can be deduced from Table 1, the neutron particle flux per unit power output is higher for D-D than for D-T reactions.

The only sense in which alternative fusion reactions could become more attractive than $\mathrm{D}-\mathrm{T}$, would be by minimizing or even eliminating the production of neutrons -- at the cost of reducing the power density and requiring substantial further advances in the Lawson diagram. The most realistic alternative of this kind, ${ }^{9} \mathrm{D}-3 \mathrm{He}$, would have some residual neutron yield from the D-D reactions -- but the (somewhat speculative) technique of nuclear polarization 10 could further suppress the D-D reactions while enhancing $\mathrm{D}-3 \mathrm{He}$. A potential obstacle to the use of $\mathrm{D}-3 \mathrm{He}$ for base-load power generation is uncertainty about the costeffectiveness of natural sources of ${ }^{3} \mathrm{He}$ fuel 11 and the lack of the kind of closed nuclear cycle that is possible with the use of tritium fuel (which can be bred from 14-MeV neutron interactions with natural lithium). If $3 \mathrm{He}-$ availability turned out to be insufficient, there is still the option of higher- $Z$ reactions such as $\mathrm{p}-6 \mathrm{Li}$, but the challenges to plasma confinement physics and technology would then become quite formidable.

\section{Energetic-Ion Minority Populations}

In the plasmas of $10-\mathrm{keV}$-range average temperature that are typically envisaged for D-T-burning reactors, the alpha-particles will deposit their energy mainly into the bulk-plasma electrons, with a slowing-down time on electrons of:

$$
\tau_{\alpha e} \propto \mathrm{T}_{e}^{3 / 2} / \mathrm{n}_{e}
$$


Since the source term of the alpha particles is proportional to $\mathrm{ne}^{2}<\sigma_{\mathrm{DT}} \mathrm{v}_{\mathrm{i}}>$, we see that the fractional alpha-particle population $\mathrm{n}_{\alpha} / \mathrm{n}_{\mathrm{e}}$ is a function only of the electron and ion temperatures. 12 We have the approximate result

$$
\mathrm{n}_{\alpha} / \mathrm{n}_{\mathrm{e}} \propto \mathrm{T}_{\mathrm{e}}^{3 / 2}<\sigma_{\mathrm{DT}} \mathrm{v}_{\mathrm{i}}>\propto \mathrm{T}_{\mathrm{e}}^{3 / 2} \mathrm{~T}_{\mathrm{i}}^{2}
$$

where around $\mathrm{T}_{\mathrm{i}} \sim 10 \mathrm{keV}$, we use $\angle \sigma D \mathrm{~T} \mathrm{v}_{\mathrm{i}}>\propto \mathrm{T}_{\mathrm{i}}{ }^{2}$. For a Maxwellian plasma (with $T_{e}=T_{i}=T$ ), the quantities $n_{\alpha} / n_{e}$ and $\beta \alpha / \beta$ th (where $\beta \alpha$ refers to the alpha-particle pressure and $\beta$ th to the bulk plasma pressure, relative to the magnetic-field pressure) are unique functions of $T$ in a plasma of given ionic composition. The corresponding curves ${ }^{13}$ for 50:50 D-T plasmas with $Z_{\text {eff }}=1$ and 2 are shown in Fig. 3, where alphathermalization with the bulk-plasma ions as well as electrons has been taken into account.

The relative population of alpha-particles in a bulk plasma of given temperature can be enhanced by a factor $\mathrm{M}_{\alpha}=\left\langle\sigma_{\mathrm{DT}} \mathrm{vi}\right\rangle_{\text {non-therm }} /$ $\left.<\sigma_{\mathrm{DT}} \mathrm{vi}\right\rangle_{\text {therm }}$ in the presence of a non-thermal energetic-ion tail. For example, in neutral-beam-heated plasmas in TFTR and JET, where maximum D-D event rates of about $8 \times 1016 \mathrm{sec}^{-1}$ have been achieved, there is roughly a five-fold enhancement of the total reaction rate relative to the thermal component of the reaction rate (Fig. 4). As the energymultiplication factor $Q=$ (fusion output power)/(input power) is raised towards its practical target value around 30 (cf. Sec. 6), thermalization becomes more intense, driving the $\mathrm{M}_{\alpha}$-factor down to unity, but the ratio $\mathrm{T}_{\mathrm{e}} / \mathrm{T}_{\mathrm{i}}$ also rises towards unity, with the net effect that the magnitudes of 
$n_{\alpha} / n_{e}$ and $\beta_{\alpha} / \beta_{\text {th }}$ in next-generation experiments (cf. Sec. 7) will not be very different from those projected for the near-term break-even-level experiments (cf. Table 2).

For Maxwellian plasmas, a simple "universal plot"14 can be constructed (Fig. 5) describing the alpha-particle-physics-related quantities that will be of principal interest in the following sections. The absolute value of $\beta \alpha$ is seen to depend on the bulk-plasma temperature and on the quantity $\mathrm{ne}_{\mathrm{e}} / \mathrm{B}^{2}$-- which happens to be proportional to the square of a number that is of critical interest in Sec. 5: namely, the ratio of the initial alpha-particle velocity to the Alfven velocity in the bulk plasma. Figure 6 uses the coordinates of Fig. 5 to plot the "universal alpha-particle heating power" $\mathrm{P}_{\alpha}{ }^{*}$ (in units proportional to $\mathrm{B}^{4}$ ). The coordinate system used in Figs. 5 and 6 has the additional virtue that Plasma Operation Contour "POPCON" plots15 [contours of required auxiliary heating power, (cf. Sec. 6)] for particular devices and assumed confinement-scaling laws can be superimposed consistently, provided that the density scale of each POPCON plot is calibrated to match, for the particular magnetic field strength being assumed. This is illustrated for a 10-T CIT case 14 in Fig. 7.

\section{Single-Energetic-Ion Phenomena}

A prerequisite for successful plasma heating is "single-particle" confinement of the alpha particles during their thermalization. Here "single-particle" refers to the confinement expected in the absence of possible "collective" alpha effects such as alpha-particle-induced instabilities treated in the next section. Single-particle phenomena can presently be calculated with some confidence, since the relevant 
background plasma properties are fairly well known. Recent experiments have confirmed several of the calculated confinement properties, using the $D-D$ analogues of the $D-T$ alpha particle.

The single-energetic-ion confinement properties of magnetic confinement systems are determined by the field line geometry and by the ion momentum. For closed-field-line axisymmetric systems such as the tokamak, conservation of toroidal canonical momentum implies that the ions remain within a distance $\Delta_{\alpha} \approx q \rho_{\alpha}(R / a)^{1 / 2}$ of the field line of their birth (ignoring collisional effects for the moment), where $\rho_{\alpha}$ is the ion gyroradius in the toroidal magnetic field and $1 / \mathrm{q}$ is the magnetic rotational transform (or inverse "safety factor"). Typical parameters for reactor-like magnetic configurations are $B \approx 5 \mathrm{~T}, \mathrm{R} / \mathrm{a} \leq 3, \mathrm{a}=200 \mathrm{~cm}, \rho_{\alpha} \approx 5 \mathrm{~cm}$, and $\mathrm{q} \leqslant 3$, so that we have $\Delta \alpha / \mathrm{a} \approx 0.1$ for $3.5-\mathrm{MeV}$ alpha particles, where $\mathrm{a}$ is the plasma radius. Therefore, axisymmetric single-particle alpha confinement should present no problem, at least at a global level, as discussed in several reviews of alpha particle physics.3-5,16,17

Careful consideration has been given to calculating the classical collisional transport of alpha particles and their energy content across the confining magnetic flux surfaces, particularly with regard to determining the alpha heating and ash-deposition profiles and their effects on the plasma burn. The main collisional process for $\mathrm{MeV}$ ions is a gradual energy transfer to background electrons, rather than large-angle scattering (just as alpha particles in a cloud chamber slow down in straight-line paths until nearly stopped). This implies that the alpha particles stay within about $q$ times one gyroradius of the field line of their 
birth, resulting in relatively low collisional diffusion. 18,19 However, detailed kinetic calculations of alphá transport must still be considered tentative, since the Maxwellian assumption for the lowest order alpha distribution function is inaccurate, and the usual mathematical ordering scheme $\Delta_{\alpha} / \mathrm{a}<<1$ is often inapplicable in local calculations. ${ }^{20,21}$

The next level of single-particle confinement physics concerns the effects of non-axisymmetry of the magnetic field. In stellarators this nonaxisymmetry or "ripple" is intrinsically large, and may lead to a substantial alpha loss due to particles which become mirror-trapped in local magnetic wells (and so no longer follow the closed field lines). ${ }^{22}$ In tokamaks the dominant ripple effect is due to the finiteness of the number of toroidal field coils $(N \approx 16-32)$, which typically introduces variations in the magnetic field strength along a field line that are in the range $0.1-1 \%$. Although this ripple is usually too small to cause significant rippletrapping, a more subtle "stochastic ripple diffusion" effect can cause rapid energetic ion loss when the ripple exceeds a threshold $\delta$ approximately given by:

$$
\delta=(\varepsilon / \pi N q)^{3 / 2} /\left(2 p q^{\prime}\right)
$$

where $\mathrm{N}$ is the number of field coils, $\varepsilon$ is the local aspect ratio (minor radius over major radius), and $\mathrm{q}^{\prime}$ is the local radial derivative of $\mathrm{q}$. This threshold can be as low as $0.3 \%, 23$ which corresponds to the typical ripple level obtained for $\mathrm{N} \sim 20$ at $\mathrm{r} \approx \mathrm{a} / 2$. Detailed Monte-Carlo calculations of this process have concluded that it can result in the loss of as much as $10 \%$ of the alpha heating power in typical reactor configurations.24-26 In fact, this 
consideration is often used to determine the minimum number of field coils allowable in reactor designs, and the requirements for local alpha wallloading protection.

The stochastic ripple diffusion theory has been generalized for arbitrary helical non-axisymmetry, 27 which is relevant when considering plasma-generated internal magnetic perturbations. A typical analytic estimate concludes that the threshold ripple level for stochastic alpha diffusion due to large-scale internal modes is several percent 28 -fortunately somewhat above the normal level of such perturbations. However, this loss process has not yet been studied with extensive numerical modelling.

Another single-particle consideration is the effect of small-scale plasma turbulence on alpha diffusion and loss. One might expect such turbulent diffusion to dominate alpha transport, as it apparently dominates thermal plasma transport. However, general theoretical considerations predict 27,28 that large-gyroradius and large banana-width particles tend to "orbit-average" the influence of any perturbations smaller than the ion gyroradius, so that the anticipated alpha transport in reactor-grade plasmas should be negligible, if the actual spectrum of turbulence turns out to be as expected. Low mode number global perturbations may however cause alpha-losses, depending on their saturation amplitude (cf. Sec. 5).

A simple and convenient summary of the various alpha-particle loss processes and their rough magnitudes (for the illustrative case of INTOR 
parameters) is given in Table III, reproduced from Ref. 28, and which is evaulated for the illustrative case of INTOR parameters.

Many experimental results on single-particle $\mathrm{MeV}$-ion confinement have already been obtained using charged fusion products from the $D-D$ and $\mathrm{D}-3 \mathrm{He}$ reactions (see Sec. 1). The $1-\mathrm{MeV}$ triton and $3-\mathrm{MeV}$ proton are particularly useful since their gyroradii and collisionality are similar to those of the $3.5 \mathrm{MeV}$ alpha particle.

Triton "burnup" experiments on several tokamaks have measured the global triton confinement and thermalization rates from the ratio of the D-T reaction rate (producing $14 \mathrm{MeV}$ neutrons) to the D-D reaction rate (producing the tritons and $2.5 \mathrm{MeV}$ neutrons). Recent results from JET are particularly encouraging, ${ }^{29}$ since they suggest nearly perfect triton confinement and classical collisional thermalization in discharges with up to 5 MA plasma current, as shown in Fig. 8. Previous results from PLT and PBX, 30-33 as well as from JET and TFTR 34 , had sometimes indicated anomalously low triton burnup, possibly associated with the internal fluctuation levels or toroidal field ripple. Classical thermalization of highenergy ions has also been re-confirmed recently with injected neutralbeam ions in DIII-D35 (the results are more consistent with those of previous experiments on various beam-heated tokamaks).

Direct measurements of triton and proton loss to the wall have also been made, particularly on the PLT and TFTR tokamaks. The latest measurements on TFTR have verified the expected reduction in triton losses as the plasma current is increased, as shown in Fig. 9.36 They have 
also shown extra MHD-induced losses in some cases, as shown in Fig. 10.34 These measurements, made at the bottom of the vessel, are at present being extended by a search for stochastic ripple losses, which are predicted to occur near the outer midplane. 37 Stochastic ripple diffusion can also be studied using perpendicular neutral beam injected ions, for example in the large plasmas of JT-60 and TORE-SUPRA.

If the single-alpha-particle loss rate were to become sufficieritly high relative to other transport processes, the associated electrostatic charge imbalance could give rise to significant plasma rotation. 38 The loss of momentum from the $3.5-\mathrm{MeV}$ alpha particles, however, is substantially lower than the momentum input from the loss (or gain) of $100-\mathrm{keV}$-range neutral-beam-injected particles with the same heating power. Accordingly, alpha-loss-driven rotation will not be large, and seems unlikely to have an important impact on confinement.

In summary, the theory of single-energetic-ion transport is rather well developed and the predicted confinement for tokamak reactors is expected to be adequate. Research in this area will concentrate on the further refinement and experimental checks of classical transport theory, 39 particularly on the assessment of the wall-loading effects of the small fraction of lost alphas.

\section{Energetic-Ion-Driven (or Stabilized) Collective Phenomena}

The most intellectually challenging issues of burning-plasma physics concern the "collective" stability of the alpha-particle population and its potential effect on confinement. There are several distinct modes of 
instability, each of which needs to be evaluated in both the linear and nonlinear range. The motivation for this study is that alpha-particle instabilities could result in the deterioration of either alpha-particle or bulk-plasma confinement, leading to a loss of ignition capability; conversely, new alpha-particle effects could help stabilize existing MHD modes, thus improving bulk-plasma confinement.

The techniques of plasma stability analysis were first applied to alpha-particle stability during the 1970's.40 The general procedure is to start by considering a simplified plasma equilibrium with a model alphaparticle population, e.g., a 1-D "slab" model with a Maxwellian alphaenergy distribution. The next step is to use either the fluid (MHD) equations or the more detailed kinetic equations (or both together) to find the linear stability of the alpha population in that equilibrium. Subsequent investigations typically diverge in two directions: either the linear stability analysis is pursued with increasingly realistic geometries and alpha populations, or a quasi-linear or non-linear stability analysis is attempted using the simplified model. Fully non-linear realistic solutions are unavailable at present; thus the challenge is to incorporate the essential physics in a tractable model. For the time being, there are few experimental resilts in this area.

Table IV lists some collective alpha effects as envisioned for D-T operation of the TFTR tokamak. 41 The frequency range of possible instabilities is $\mathrm{f} \sim 10^{1}-10^{9} \mathrm{~Hz}$, reflecting a variety of theoretically predicted instabilities and demanding a wide range of diagnostic capabilities. Similar considerations apply to D-T operation of JET. 42 
In the low-frequency range $\mathrm{f}<50 \mathrm{kHz}$, alphas can affect the wellknown MHD kink modes (sawtooth, fishbone). These are helical low-m magnetic modes which exist in ordinary tokamak plasmas, and which can be either stabilized or destabilized by energetic ions. Potentially the most dangernus of these is the "fishbone" instability, named for the skeletonshaped patiern of magnetic fluctuations observed when injected neutralbeam ions first created this instability in the PDX tokamak. 43 Present theory identifies this effect as a resonance between the energetic trappedion toroidal precession frequency and a preexisting ideal $n=1$ MHD kink mode.44-47 Predictions of alpha-induced fishbone thresholds for TFTR and for the proposed Compact Ignition Tokamak (CIT) are shown in Fig. 11.48 If this modeling is correct, the fishbone mode could be active at normal plasma burn temperatures in the $20 \mathrm{keV}$ range, possibly resulting in substantial loss of alpha particles to the wall 31 (fishbone mode might also have a beneficial effect by exhausting nearly thermalized alphas). On the other hand, the alpha population has the potential to help stabilize the common $m=1$ internal kink mode, $45,46,48$ which could significantly improve bulk plasma confinement near the center of alpha-heated plasmas (as in ICRF-heated JET plasmas). Another beneficial effect might be obtained if the alpha-driven fishbone mode were to help eject nearlythermalized alphas.

In the middle frequency range $\mathrm{f} \approx 50-500 \mathrm{kHz}$, alphas can affect the small-scale drift and high-n ballooning modes. These instabilities are often thought to cause "anomalous" thermal plasma transport in present tokamaks, but are not well-diagnosed experimentially. Alphas couid 
resonantly drive these modes at the alpha toroidal transit or bounce frequency, potentially causing degraded bulk plasma confinement. Linear stability effects have been evaluated using kinetic theory with realistic geometry, $49-52$ as shown for example in Figs. $12^{49}$ and 13.52 Fortunately the predicted effect on drift modes is negligible; however, the threshold $\beta$ for kinetic ballooning modes can be reduced substantially, at least for this CIT case.

In the high frequency range $\mathrm{f} \simeq 100-500 \mathrm{KHz}$, several new Alfven wave instabilities can be excited when the alpha velocity exceeds the Alfven wave velocity. These modes are generally unfamiliar to tokamak experimentalists, since large populations of super-Alfvenic ions are not normally present. The most dangerous of these modes seems to be the toroidicity-induced Alfven eigenmode, of both low $\mathrm{n}$ and high $\mathrm{n}$ varieties, which has been the subject of recent MHD and kinetic analyses.53-58 Although linear instability of this TAE mode has been predicted for typical burning-plasma parameters, as shown in a simplified local analysis in Fig. 11, (from Ref. 55) the effects of the mode on confinement depend upon the non-linearly saturated level of the mode. (The inverse linear growth rate is $-10^{-3}$ sec so non-linear saturation is expected.) A recent MonteCarlo calculation ${ }^{54}$ of the alpha transport due to an assumed mode level of $\widetilde{\mathrm{B}}_{\mathrm{r}} / \mathrm{B}_{\mathrm{T}}>10^{-4}$ predicts very significant losses of untrapped alpha particles, potentially ejectir. $g$ bursts of alphas before they can deposit an appreciable part of their energy in the plasma. A typical unconfined single-particle orbit in the presence of such a mode is shown in Fig. 14. Alfven instabilities 
driven by a velocity-space loss cone arising from ripple losses constitute another potentially serious mechanism for the ejection of alpha particles. 59

The uncertainties involved in theoretical predictions of collective alpha effects have already motivated several attempts to simulate the relevant physics before attempting a burning-plasma experiment. One method would be to use the sub-ignition D-T experiments on TFTR and JET to maximize the alpha parameters $\beta_{\alpha}$ and $n_{\alpha} / n_{e}$, since in fact reactorrelevant alpha parameters can be anticipated. 41,60

Another powerful simulation technique available in existing plasmas uses energetic "minority" tail ions routinely created by ion-cyclotron radiofrequency heating. In recent JET experiments, a $3 \mathrm{He}$ minority population with a temperature of $>1 \mathrm{MeV}$ was formed, which contained $\sim 50 \%$ of the plasma stored energy 60,61 -- more than the $10 \%$ of stored energy typically expected for alphas in D-T plasmas. So far no plasma confinement degradation or anomalous loss of the ions was observed, except for some indications of sawtooth or high- $\beta$ MHD-induced losses. However, one difficulty is that rf-accelerated minority ions are not isotropic in velocity space like the alphas, but tend to be mostly trapped. As a consequence they may not be able to drive the toroidicity-induced Alfven mode. It is also not yet clear what fraction of these rf-accelerated ions is super-Alfvenic.

The special limitations associated with perpendicular minority tail ions can be avoided by additional simulations with an injected neutral beam, which can form a well-characterized and dominantly parallel super-Alfvenic ion population when a low magnetic field is used in present 
tokamaks $(\approx 1 \mathrm{~T})$. Preliminary experiments along this line are presently being conducted on DIII-D62 and TFTR,63 but it is still difficult to satisfy $\mathrm{v}_{\text {beam }}>\mathrm{v}_{\text {Alfven }}$ with present neutral beam systems. Future experiments on JT- 60 plan to inject $\approx 10 \mathrm{MW}$ of $500 \mathrm{keV}$ neutral beams (produced by negative ion sources), which should produce a substantial parallel superAlfvenic population for further study of the TAE mode. This injection scheme on JT-60 is also expected to produce $\approx 1 \mathrm{MW}$ of alpha particle power (from $\mathrm{D}-{ }^{3} \mathrm{He}$ reactions) to provide an even more realistic test of collective alpha physics.

\section{Fusion-Heat Driven Collective Phenomena}

Tokamak plasma confinement has been found to deteriorate as a function of rising plasma-heating power. The question has been raised, whether alpha heating will have the same effect on transport as "ordinary" auxiliary heating. Present experimental evidence suggests that the transport-enhancing effect is related to the magnitude of the plasmaheat outflow through the plasma edge -- not to the nature of the heat input in the plasma core. This issue is of such fundamental importance, however, as to call for direct experimental verification. In particular, the response of the plasma confinement to central electron heating by alphas in the regime $T_{i} \sim T_{e} \sim 10-20 \mathrm{keV}$ needs to be understood.

The auxiliary-heating power that is required to maintain a burning plasma in thermal equilibrium is a function of the plasma temperature and density and their profile shape (cf. the "POPCON" diagram,64,65 Fig. 7) as well as of other parameters, such as the ionic composition of the plasma and the strength, size, and geometry of the confining magnetic field 
configuration. Unlike the plots shown in Figs. 5 and 6, which display "universal" features of the alpha-particle population, POPCON plots depend strongly on the particular model that is being used to describe the enhancement of the heat and particle transport coefficients beyond their neoclassical values.

POPCON plots do tend, however, to have certain common topological features: when plasma confinement is sufficiently good, as in the example of Fig. 7, the upper curve on which the required auxiliaryheating power $P_{a u x}$ vanishes is accessible within the constraints set by the Troyon beta limit66 and (perhaps less strongly) by the Hugill-MurakamiGreenwald density limit.67 In that case, there tends to be a clear path of minimum auxiliary-heating power which is called the "Cordey Pass."68 Since the convention of POPCON plots does not include ohmic heating as part of the auxiliary-heating-power requirement Paux, there is also a lowtemperature curve where $P_{a u x}=0$. The Cordey Pass leads from the lowtemperature to the high-temperature $\mathrm{Paux}=0$ curve, going through a saddle point in the $\mathrm{P}_{\mathrm{aux}}$-requirement. If the plasma density and $\mathrm{Paux}$ were maintained for a plasma that has gone over the top of the Cordey Pass, the plasma temperatures would tend to rise spontaneously. This kind of thermal instability on the far side of the Cordey Pass is sometimes called "ignition," though the local Q-value, defined in the usual way as $\mathrm{Q} \equiv \mathrm{PF} / \mathrm{PH} \equiv \mathrm{PF}_{\mathrm{F}} /(\mathrm{POH}+\mathrm{Paux})$ is typically only about 5 (cf. Fig. 15).

An alternative definition of the term "ignition" refers to $Q=\infty$. This condition is approximated by the upper $\mathrm{Paux}_{\mathrm{aux}}=0$ curve in Fig. 15, but cannot be reached in a literal sense by tokamak plasmas, since the ohmic- 
heating power never quite vanishes. A more physically appealing way of stating the definition of ignition is in terms of the ignition margin

$$
\mathrm{M}_{\mathrm{I}}=\gamma_{\alpha} \mathrm{P}_{\mathrm{F}} / \mathrm{P}_{\mathrm{L}}
$$

(cf. Fig. 16), where the quantity $\gamma_{\alpha}$ refers to the fraction of the fusionpower that is thermalized within the plasma (e.g., $\gamma_{\alpha}=0.2$ for perfect alpha-particle confinement), and where $P_{L}$ is the total plasma heat-loss power. The ideal condition for equilibrium burn, corresponding to $Q=\infty$, is $\mathrm{M}_{\mathrm{I}}=1$. The presence of residual ohmic heating pushes the limit of thermal equilibrium slightly below $M_{I}=1$. Conversely, if the operating point in Fig. 16 is above $\mathrm{M}_{\mathrm{I}}=1$, the plasma undergoes a thermal excursion: The temperature rises dynamically (at a rate deternined by $M_{I}=1$ and by the plasma heat capacity) until it encounters the $M_{I}=1$ limit again on the high- $\mathrm{T}$ side.

Even when the ignition margin is consistent with the preservation of thermal equilibrium (i.e., $\mathrm{M}_{\mathrm{I}}<1$ ), the equilibrium state may be thermally unstable. As Fig. 16 indicates, this is typically the case for plasmas that have gone through the Cordey Pass and arrived at the low- $\mathrm{T}$ end of the $\mathrm{M}_{\mathrm{I}}=1$ curve. The existence of thermal instability in the low- $\mathrm{T}$ range tends to be inconvenient for fusion reactors, since the most desirable reactoroperating temperature typically falls within the thermally unstable range -- being limited by considerations of maximizing $\mathrm{P}_{\mathrm{F}}$ within a constraint on the plasma pressure (cf. Fig. 2) or by concerns about the plasma edge temperature and associated impurity generation. As a result, there has been strong interest in developing "burn control" in the form of a feedback 
system that acts to clamp the plasma temperature at the desired operating point.69. Proposals for such a control mechanism include modulation of the degree of axisymmetry of the toroidal magnetic field 70 (i.e., modulation of the "field ripple"), with a view to controlling the single-particle alpha-loss (cf. Sec. 4), modulating the residual heating power to provide negative feedback as well as various other techniques, $71-73$ for reducing $\gamma_{\alpha}$ or increasing $\mathrm{P}_{\mathrm{L}}$. Practical tokamak reactor designs call for $\mathrm{Q}$-values in the range $\leqslant 30$, rather than $Q \rightarrow \infty$. (This results from the need to maintain a seed current even in a bootstrap current driven configuration. ${ }^{74}$ )

When plasma confinement is sufficiently poor, the POPCON plots take on quite a different topology, as illustrated in Fig. 17, with the Cordey Pass disappearing and the upper $\mathrm{Paux}_{\mathrm{a}}=0$ curve moving out of reach. Not surprisingly, the tendency towards global thermal instability disappears along with the ignition potential. Comparison of Figs. 17 and 18 shows that even the attainment of $\mathrm{Q}$-values appreciably above unity then tends to impose demanding requirements in terms of auxiliary heating power.

Aside from the tendency towards global thermal instability, in plasmas with $\mathrm{M}_{\mathrm{I}} \rightarrow 1$, the tokamak is well known to give rise to $\underline{\text { local }}$ thermal instability phenomena. The ordinary "saw tooth" mechanism 75 of non-burning plasmas consists of two phases: (1) a slow thermal excursion at the plasma center, accompanied by a peaking of the central current density profile and a decline of the MHD safety factor $\mathrm{q}(0)$; (2) periodic appearance of a rapidly growing $m=1, n=1$ kink mode that leads to a local "disruption" and flattening of the central $\mathrm{T}(\mathrm{r})$-profile, thus restoring the status quo. In a hot D-T plasma, the sawtooth mechanism is 
reinforced by local alpha-particle heating, 76 which drives up the destabilizing central $\beta$-value -- an effect that can remain significant even when the POPCON diagram does not indicate global thermal instability. On the other hand, the presence of a sizable alpha-particle minority can also exert a finite-gyroradius stabilizing effect on the threshold for the $\mathrm{m}=1, \mathrm{n}=1 \mathrm{kink}$ mode (cf. Sec. 5). Actual experiments will be required to reveal the dominant physical mechanism.

Present-day tokamak experiments can be said to "simulate $\alpha$-particle heating" in a gross sense whenever the spontaneous ohmic heating is supplemented by auxiliary heating power. Much more sophisticated forms of simulation could be realized by modulating the auxiliary power source -- for example, an ICRF source that helps energize the minority alpha-particle population 77 -- in response to an algorithm based on local plasma diagnostics. A primitive example would be a feedback loop where the plasma-heating power $\mathrm{P}_{\mathrm{H}}$ is adjusted so as to remain proportional to the measured neutron flux from a D-D or D-T plasma: The effect would be to multiply the reactivity $\angle \sigma_{D D} v_{i}>$ of a deuterium plasma to make it behave (grossly) like a deuterium-tritium plasma, or to multiply the apparent reactivity of a deuterium-tritium plasma, so as to make it "ignite" well below the usual requirements on $n \tau_{E}$ and $T$. A more complex algorithm, based on local plasma temperature and density measurements, could come even closer to simulating the thermal excursions of burning plasmas -- but the need to put the full set of complex interactions between alpha-particle-driven and fusion-heat-driven phenomena to a definitive test still points to the critical need for "real" burning-plasma experiments. 


\section{Future Burning-Plasma Experiments}

\section{J.1 Research Needs}

The development of fusion power will require improved physical understanding and engineering techniques in a number of areas not directly associated with fusion burn. Planning for experiments that aim to study the physics of burning plasmas must take into consideration the long-term research needs for the development of safe, economic fusion power, as well as the specific needs for burning plasma physics studies. Fusion research needs can be arranged into a hierarchy of physics and engineering research and development $(R \& D)$ areas.

The main physics $R \& D$ areas are:

1. Confinement

$\mathrm{n}(0) \mathrm{T}(0) \tau_{\mathrm{E}}>6 \times 10^{21} \mathrm{keV} \mathrm{sec} / \mathrm{m}^{3}$ at $\mathrm{T}(0)>20 \mathrm{keV}$

If helium ash builds up to $0.1 \mathrm{n}_{\mathrm{e}}$, this requirement increases by $\sim 50 \%$.

2. Plasma heating, fueling, and impurity control:

Heating, fueling, and impurity control techniques compatible with long-pulse ignited plasma operation.

3. $\alpha$ collective stability

$\mathrm{T}(0)>20 \mathrm{keV}, \beta_{\alpha}(0)>1 \%$

Stability tests for current-drive regimes require $\sim 50 \%$ higher parameters. 
4. $\alpha$ heating

$$
\mathrm{Q}>5
$$

This hcating provides entry into the self-heated plasma regime.

5. Burn control

$Q>20$

Minimum $Q$ for reactor economics. Interesting for burn pulses

$\tau_{\text {burn }}>5 \tau_{E} ;$ pulses with $\tau_{\text {burn }}>\tau_{\text {skin }}$ are even more interesting.

6. Effective helium ash removal

$\tau_{\mathrm{He}}{ }^{*}<i 0 \tau_{\mathrm{E}}$ required, where $\tau_{\mathrm{He}}{ }^{*}$ is the residence time of helium (thermalized alphas) in the system.

The main engineering R\&D areas are:

7. Adequate power outflow handling

Techniques to handle power outflow corresponding to $1-5 \mathrm{MW} / \mathrm{m}^{2}$ of neutron flux.

8. Disruption control and survival

Techniques to reduce disruptivity and to survive disruptions.

9. Efficient steady-state current drive

$Q>20$ where $P_{\text {aux }}$ (in $Q \equiv P_{F} / P_{\text {aux }}$ ) is the current drive power.

10. Development of large-scale superconducting magnets $\mathrm{R} \sim 7 \mathrm{~m}, \mathrm{~B}_{\text {coil }}>12 \mathrm{~T}$. 
11. Tritium breeding

Breeding ratio $>1$.

12. Efficient electricity generation

$>30 \%$ net efficiency.

13. High duty factor and remote maintenance in nuclear environment Duty factor $>\sim 75 \%$.

14. Development of nuclear-compatible materials Low activation, first-wall lifetime $\sim 20 \mathrm{MW}-\mathrm{Y} / \mathrm{m}^{2}$.

Many of these fusion R\&D issues [items (1) to (8)] can be substantively addressed in a sub-ETR (Engineering Test Reactor)-scale $D$-T-burning physics experiment. The confinement requirements for such a device are comparable to those for an ETR, but in the absence of steady-state and reactor nuclear requirements, such a device can be substantially smaller and less complex than a full-scale ETR, which must address all, or nearly all, of these items in a single integrated system test.

\subsection{Experimental Options for Burning Plasmas}

In the context of the fusion R\&D needs outlined above, it is clear that a number of different strategies are possible. A burning-plasma experiment can limit itself to items (1) to (4), or can take on any further subset of the list of needs, up to and including the full list. Each of these items can be addressed at different levels of completeness, e.g., burn 
control can be addressed only for short pulse, or steady-state current drive can be addressed only at low efficiency.

The world fusion community is presently finishing a joint study for the conceptual design of an ETR-type device, the ITER 78 (International Thermonuclear Experimental Reactor). Burning plasma physics and engineering experiments on a device of this class will call for a large investment, but would be especially enlightening, since the plasma most closely approaches the characteristics of a fusion reactor plasma. According to present plans, ITER will be ready to start D-T operations around the year 2006 -- about one decade after the end of the TFTR-JET $\mathrm{D}-\mathrm{T}$ research phase. During the intervening time, valuable information in support of ITER, and of fusion research in general, could flow from a near-term alpha-physics experiment. While ITER's basic TF ar I PF coil system designs will be fixed relatively early, its iniernal power-handling, disruption hardening, diagnostic systems tritium handling systems, remote-maintenance equipment, and plasma heating, fueling, and exhaust systems could all be modified in response to practical results from such an experiment.

Confinement and divertor performance results from a near-term high-Q burning-plasma experiment could help guide the inevitable engineering trade-offs between plasma performance capability and engineering risk, which will be required during final design of ITER's internal hardware. Measurements of $\alpha$ ash build-up and transport could have important impacts on divertor and pumping designs. Data on the effects of high-current disruptions in a conducting vacuum vessel would 
also be most valuable for engineers designing the in-vessel tritium breeding modules and first-wall armor for ITER. If collective $\alpha$ effects were found to become substantially deleterious at high plasma temperature (i.e., high $\alpha$ pressure), this finding would have very important implications for the ITER heating and current drive systems, and on planning for the technology phase. Effects of alpha particles on the operating limits may govern the operating values of $\beta, n_{e}$ and the safety factor $\mathrm{q}$. This could also have significant impacts on the planning for ITER operation.

A D-T burning plasma experiment that aims to provide useful support of the sort outlined above for the ITER program should be substantially $(\sim x 10)$ less expensive than ITER, and will need to be constructed much more quickly. Empirically observed scaling relations 79 and theoretical scaling arguments 80 show that if size is scaled down, but the magnetic field is scaled up from a putative reactor, to a smaller, higher-field tokamak, such a device can be expected to reach reactorlike values of $\mathrm{nT} \tau$. Thus one can envision a relatively compact, high-field tokamak able to provide cost-effective, reactor-relevant information on confinement at high nTr. At the same time, it would have the performance required for high $Q$ operation. For the purpose of alpha physics, it is necessary to maintain the Alfven speed constant compared to a large $B \approx 5 T$ superconducting reactor; as a result the smaller device must have the plasma density scaled from the reactor as $B^{2}$. This is a natural consequence of the Hugill-Murakami-Greenwald density limits, so long as the device size scales roughly as $1 / \mathrm{B}$. This scaling also fits well with the desire to operate such a device at the same volume average $<\mathrm{T}>$ 
and $\beta$ as a reactor, also to obtain the most relevant $\alpha$ physics. Thus a modest-sized, high-field D-T burning experiment would provide near term information both on high $\mathrm{nT} \tau$ confinement, and also on burning plasma physics.

In addition, such a device would naturally provide valuable fusion engineering information. In the areas of power-outflow-handling and impurity control, studies on such a device would be both stipportive of, and complementary to, ITER. While the pulse length would be much shorter than ITER's, the areal power density at fixed $\beta$ would be greater, comparable to what is required for an economic fusion reactor. ${ }^{81}$ Indeed the limit to the high-field, small-size D-T burning experiment approach is set by the projected power-handling capability.

\subsection{Summary}

The design of a burning plasma experiment must be set in the context of the overall physics and engineering R\&D needs for fusion power. A compact, high-field D-T burning-plasma device would provide substantial confinement, $\alpha$ physics, and fusion engineering support for the ITER project, and for devices beyond ITER. Such an experiment would need to be relatively inexpensive and expeditious to provide costeffective information on the required time scale. The final, integrated test of $\alpha$ physics and long-pulse burn must be performed on an ETR-scale device such as ITER. 


\section{Conclusions}

The favorable and unfavorable interactions of alpha-particle populations with their D-T source plasmas have important impacts on reactor-plasma performance that cannot be ignored in the process of reactor-concept development and optimization. These interactions can be explored to some extent in non-burning or weakly burning-plasmas, but the physics is sufficiently complex so that high-Q, D-T-burning nearterm experiments will be desirable to provide substantial confidence in our scientific understanding of the burning plasma state. Long-pulse, high-duty-cycle facilities of the ITER kind and beyond will then serve to provide a firm basis for the development of fusion reactor technology.

\section{Acknowledgements}

This work was supported by United States Department of Energy Contract No. DE-AC02-76-CHO3073. 
$-28-$

Table 1

Fusion Reactions of Principal Interest

$\begin{aligned} \mathrm{D}+\mathrm{T} & =\mathrm{n}(14.1 \mathrm{MeV})+\alpha(3.5 \mathrm{MeV}) \\ \mathrm{D}+\mathrm{D} & =\mathrm{n}(2.5 \mathrm{MeV})+3 \mathrm{He}(0.8 \mathrm{M} \mathrm{V}) \\ \text { or } & =\mathrm{T}(1 \mathrm{MeV}) \\ \mathrm{D}+3 \mathrm{He} & =\mathrm{p}(14.7 \mathrm{MeV})+\alpha(3 \mathrm{MeV})\end{aligned}$




\section{Table 2}

Alpha-Particle Plasma Physics Parameters

\begin{tabular}{|c|c|c|c|c|c|}
\hline \multirow[b]{3}{*}{ Parameter } & Current & & CIT & CIT & \multirow[b]{3}{*}{ ITER } \\
\hline & TFTR-JET & TFTR-JET & Low & High & \\
\hline & $\mathrm{DT}_{\text {projected }}$ & Objective & $\mathrm{T}$ & $\mathrm{T}$ & \\
\hline $\mathrm{n}_{\alpha}(0) / \mathrm{ne}_{\mathrm{e}}(0)$ & $0.3-0.5 \%$ & $0.5-1 \%$ & $0.1 \%$ & $0.9 \%$ & $0.7 \%$ \\
\hline$\beta \alpha(0)$ & $0.3-0.6 \%$ & $0.5-1.5 \%$ & $0.2 \%$ & $2.5 \%$ & $2.3 \%$ \\
\hline$v_{\alpha} / v_{\text {Alfven }}$ & $1.5-2.0$ & 1.7 & 2.5 & 2.6 & 2.8 \\
\hline
\end{tabular}




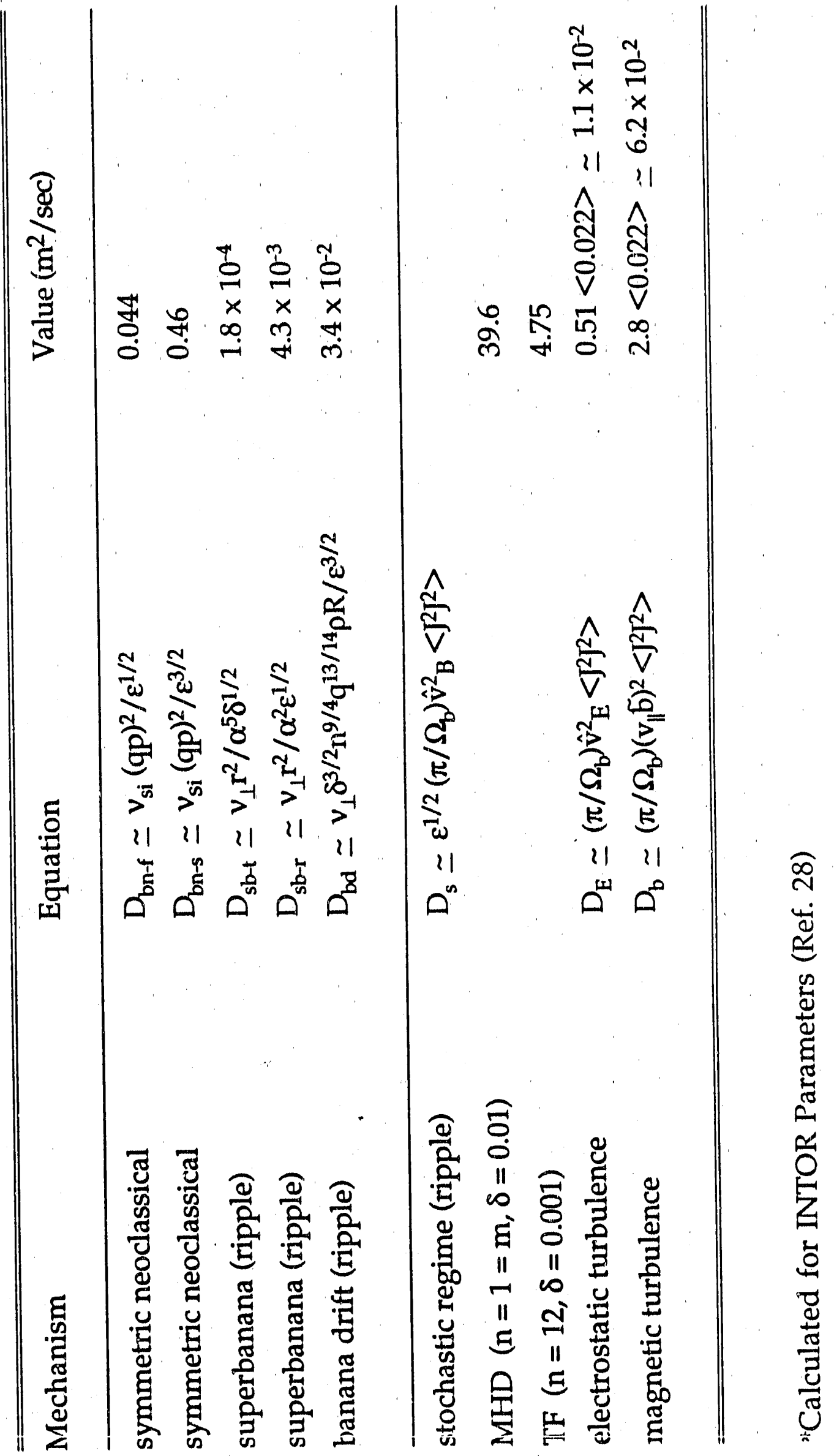




\section{Table 4}

\section{Collective Alpha Instabilities}

\begin{tabular}{|c|c|c|c|c|c|}
\hline Instability & $\begin{array}{l}\text { Frequency } \\
(\mathrm{kHz})\end{array}$ & $\begin{array}{l}\text { Physical } \\
\text { Mechanism(s) }\end{array}$ & $\begin{array}{l}\text { Important } \\
\text { Parameters }\end{array}$ & $\begin{array}{l}\text { Possible } \\
\text { Eftects }\end{array}$ & $\begin{array}{l}\text { TFTR } \\
\text { Diagnostic(s) }\end{array}$ \\
\hline $\begin{array}{l}\text { Alpha Driven } \\
\text { Sawteeth }\end{array}$ & $<0.1$ & $\begin{array}{l}\text { Central Electron } \\
\text { heating by } \\
\text { alphas } \rightarrow \\
\text { sawtootli crash }\end{array}$ & $\frac{P_{\alpha}(0)}{P_{\text {heat }}(0)}$ & $\begin{array}{l}\text { Modification } \\
\text { of } q(r) \text { pro- } \\
\text { file; expulsion } \\
\text { of } \alpha \text { 's from } \\
\text { center }\end{array}$ & $\begin{array}{l}\text { Gyrotron } \quad \alpha \\
\text { Scattering } \\
\text { soft X-ray } \\
\text { emission }\end{array}$ \\
\hline $\begin{array}{l}\text { Alpha-Driven } \\
\text { Fishbones }\end{array}$ & $\sim 10^{1}-10^{2}$ & $\begin{array}{l}\text { Resonance of } \alpha \\
\text { precession and } \\
\text { internal } m=1 \\
\text { mode }\end{array}$ & $\begin{array}{l}\beta_{\alpha}(0) \\
\beta_{t h} \\
\omega_{d \alpha} / \omega_{A}\end{array}$ & $\begin{array}{l}\text { Expulsion of } \\
\text { trapped } \\
\text { alphas from } \\
\text { center }\end{array}$ & $\begin{array}{l}\text { Escaping } \\
\text { Alpha } \\
\text { detectors }\end{array}$ \\
\hline $\begin{array}{l}\text { Alpha-Driven } \\
\text { Drift Wave or } \\
\text { Ballooning } \\
\text { Modes }\end{array}$ & $\sim 10^{1}-10^{3}$ & $\begin{array}{l}\text { Resonance of al- } \\
\text { phas with } \mathrm{m}>> \\
1 \text { modes }\end{array}$ & $\begin{array}{l}\text { Gradients } \\
\text { of } \beta_{\alpha} \text { and } \\
\mathrm{n}_{\alpha} / \mathrm{n}_{e}\end{array}$ & $\begin{array}{l}\text { Reduction of } \\
\text { beta limit; } \\
\text { change of } \\
\text { plasma } \\
\text { transport }\end{array}$ & $\begin{array}{l}\mu \text { wave scat- } \\
\text { tering } \\
\text { escaping al- } \\
\text { pha detectors }\end{array}$ \\
\hline $\begin{array}{l}\text { Alpha-Driven } \\
\text { Alfven Waves } \\
\text { (e.g., TAE } \\
\text { mode) }\end{array}$ & $\sim 10^{3}-10^{4}$ & $\begin{array}{l}\text { Passing alphas } \\
\text { with } v_{\alpha}>v_{A} \\
\text { excite Alfven } \\
\text { modes }\end{array}$ & $\begin{array}{l}\mathrm{v}_{\alpha} / \mathrm{v}_{A} \\
\omega_{* \alpha} / \omega_{A} \\
\nabla \beta_{\alpha}\end{array}$ & $\begin{array}{l}\text { Anomalous } \\
\text { loss of passing } \\
\text { alphas; elec- } \\
\text { tron heating }\end{array}$ & $\begin{array}{l}\mu \text { wave } \\
\text { scattering } \\
\text { external } \tilde{B}\end{array}$ \\
\hline $\begin{array}{l}\text { Alpha-Loss } \\
\text { Cone-Driven } \\
\text { Alfven Waves }\end{array}$ & $\sim 10^{4}-10^{5}$ & $\begin{array}{l}\text { Velocity space } \\
\text { instability near } \\
\text { trapped/passing } \\
\text { boundary }\end{array}$ & $\begin{array}{l}\text { TF Ripple } \\
\mathrm{n}_{\alpha} / \mathrm{n}_{e} \\
\omega_{c \alpha}\end{array}$ & $\begin{array}{l}\text { Anomalous } \\
\text { loss of } \\
\text { trapped } \\
\text { alphas; ion } \\
\text { heating }\end{array}$ & $\begin{array}{l}\text { Ion cyclotron } \\
\text { emission } \\
\text { escaping al- } \\
\text { pha detectors }\end{array}$ \\
\hline $\begin{array}{l}\text { Alpha- } \\
\text { Population- } \\
\text { Inversion } \\
\text { Driven Alfven } \\
\text { Wave }\end{array}$ & $210^{5}-10^{6}$ & $\begin{array}{l}\text { Bump-on-tail in- } \\
\text { stability due to } \\
\text { fast alpha turn- } \\
\text { on }\end{array}$ & $\frac{1}{S_{\alpha}} \frac{\partial}{\partial t}\left(S_{\alpha} \tau_{\alpha}\right)$ & $\begin{array}{l}\text { Anomalous } \\
\text { alpha } \\
\text { slowing- } \\
\text { down; ion } \\
\text { heating }\end{array}$ & $\begin{array}{l}\text { Ion cyclotron } \\
\text { emission } \\
\text { escaping } \\
\text { alpha detec- } \\
\text { tors }\end{array}$ \\
\hline
\end{tabular}

Symbols: $\omega_{d \alpha}=$ alpha precession f́requency; $\omega_{A}=$ Alfven frequency, $\omega_{c \alpha}$ alpha cyclotron frequency, $\omega_{* A 4}=$ alpha diamagnetic frequency, $\mathrm{S}_{\alpha}=$ alpha source rate. 


\section{References}

1. Anderson, D., Hamn, H., and Lisak, M. Thermonuclear Tokamak Plasmas in the Presence of Fusion Alpha Particles, EUR-FU /80-88-91, (December 1988), Chalmers University of Technology, Goteborg.

2. Kolesnichenko, Ya.I. and Sigmar, D.J., "Alpha Particles in Fusion Research" Proc. IAEA Tech. Committee Meeting, Kiev, October 1989 [Conf. summary paper, Nucl. Fusion, 30 (1990) 777].

3. Sigmar, D.J., Phys. Scripta (Sweden) T16 (1987) 6.

4. Itoh, K., Ueda, N., Itoh, S.-I., and Sugihara, M., Japanese J. Applied Phys. 27 (1988) 1750.

5. Nakamura, H., Tobita, K., Koide, Y., et al., "Initial Results of Helium Ash Experiment in JT-60 Lower Divertor," Proc. IAEA Tech. Committee Meeting on Alpha Particle Confinement and Heating (Kiev, 1989). [To be published in Fusion Technol. 18, \#3, Nov. 1990.]

6. Conn, R.W., in Fusion, edited by Edward Teller (Academic Press, Inc., New York, 1981) Vol. I, Part B, Chapter 14, 193.

7. Conn, R.W., et al., Fusion Reactor Economic, Safety, and Environmental Prospects, in Status of Fusion, Nucl. Fusion (to be published).

8. Baker, C.C., Abdou, M.A., DeFreece, D.A., et al., Starfire -- A Commercial Tokamak Fusion Power Plant Study Argonne National Laboratory Report ANL/FPP-80-1 (September, 1980).

9. Kulcinski, G.L., Emmert, G.A., Blanchard, J.P., et al., Fusion Technol. $\underline{15}$ (1989) 1233.

10. Kulsrud, R.M., Valeo, E.J., and Cowley, S.C. Nucl. Fusion 26 (1986) 1443. 
11. Wittenberg, L.J., Santarius, J.F., and Kulcinski, G.L., Fusion Technol. 10 (1986) 167 .

12. Houlberg, W., "Modeling Alphas in a Tokamak," Proc. Alpha Particle Effects Workshop, Courant Institute, N.Y. (December 1985).

13. Post, D., Applied Atomic Collision Physics 2 (1984) 381.

14. Parker, R., Batemen, G., Colestock, P., Furth, H., et al., Plasma Phys. Cont. Nucl. Fusion Research (Nice, France) III (1989) 341.

15. Houlberg, W. and Attenberger, S., Nucl. Technol. Fusion 4 (1983) 129.

16. Y.olesnichenko, Ya.I., Nucl. Fusion 20 (1980) 727.

17. Lisak, M. and Wilhelmsson, H., Eds., "The Role of Alpha Particles in Magnetically Confined Fusion Plasmas", Physica Scripta T16, 1987, p.3.

18. Hively, L.M. and Miley, G.H., Nucl. Fusion 20 (1980) 969.

19. Belikov, V.S., Kolesnichenko, Ya.I., and Yavorskij, V.A., Fusion Technol. 15 (1989) 1365.

20. Goloborod'ko, V. Ya., Kolesnichenko, Ya.I., and Yavorskij, V.A., Nucl. Fusion 25 (1983) 399.

21. Hsu, C.T., Catto, P.J., and Sigmar, D.J., Phys. Fluids B2 (1990) 280.

22. Nagornyj, V.P. and Yavorskij, V.A., Sov. J. Plasma Phys. 15 (1989) 309.

23. Goldston, R. J., White, R.B., and Boozer, A.H. Phys. Rev. Lett $\underline{47}$ (1983) 647.

24. Hively, L.M. and Rome, J.A., Nucl. Fusion 30 (1990) 1129.

25. Tani, K., Takizuka, T., Azumi, M., and Kishimoto, H., Nucl. Fusion $\underline{23}$ (1983) 657.

26. Tani, K., Takizuka, T., and Azumi, M., "Ripple Loss of Alpha Particles in ITER," Japan Atomic Energy Research Institute Report JAERI-M89-086 (1989). 
27. Mynick, H.E. and Duvall, R.E., Phys. Fluids B 1 (1989) 750.

28. White, R.B. and Mynick, H.E., Phys. Fluids B 1 (1989) 980.

29. Conroy, S., Jarvis, O.N., Sadler, G., and Huxtable, G.B., Nucl. Fusion $\underline{28}$ (1989) 2127.

30. Heidbrink, W.W., Chrien, R.E., and Strachan, J.D., Nucl. Fusion $2 \underline{3}$ (1983) 917.

31. Heidbrink, W.W., Hay, R., and Strachan, J.D., Phys. Rev. Lett. $\underline{53}$ (1984) 1905.

32. Batistoni, P., Martone, M., Pillon, M., Podda, S., and Rapisarda, M., Nucl. Fusion $\underline{27}$ (1987) 1040.

33. Heidbrink, W.W., Lovberg, J., Strachan, J.D., and Bell, R.E., Nucl. Fusion 27 (1987) 129.

34. Strachan, J.D., et a1., Plasma Phys. Controlled Nuclear Fusion Research (Nice, France) I (1989) 257.

35. Heidbrink, W.W., Phys. Fluids $\underline{B 2}$ (1990) 4.

36. Zweben, S.J., Nucl. Fusion 30 (1990) 1551.

37. Goloborod'ko, V. Ya. and Yavorskij, V.A., Nucl. Fusion 29 (1989) 1025.

38. Hulbert, G.W., and Perkins, F.W., in Theory of Fusion Plasmas, Vaclavik, J., Troyon, F., Sindoni, E., Eds. (Editrice Compositori, Bologna, 1989) 417.

39. Becoulet, A., Gambier, D., Grua, P., Rax, J., and Roubin, J., Proc. 16th European Conf. on Cont. Fusion and Plasma Physics, Venice I (1989) 267.

40. Mikhailovski, A.B., in Reviews of Plasma Physics, Vol. 9, edited by Leontovich, M.A. (Consultants Bureau, N.Y., N.Y.) 1986, 103.

41. Zweben, S.J., Furth, H.P., Mikkelsen, D.R., Redi, M.H., and Strachan, J.D., Nucl. Fusion $\underline{28}$ (1988) 2230. 
42. Thomas, P.R., "Fast Particles in Plasmas and Alpha Particle Physics," Joint European Torus Report JET-P(89) (1989) 39.

43. McGuire, K., Goldston, R., Bell, M., et al., Phys. Rev. Lett. 50 (1983) 891.

44. Chen, L., et al., Plasma Phys. Controlled Nuclear Fusion Research (Nice, France) II (1989) 77.

45. Coppi, B., Migliuolo, Pegoraro, F., and Porcelli, F., Phys. Fluids B2 (1990) 927.

46. Zhang, Y.Z., Berk, H.L., and Mahajan, S.M., Nucl. Fusion $\underline{29}$ (1989) 848.

47. Cheng, C.Z., Proc. IAE.A Tech. Committee Meeting on Alpha Particles in Fusion Research, Kiev (1989) [Fusion Technol. 18 \#3, Nov. 1990].

48. White, R., Romanelli, F., and Bussac, M.N., Phys. Fluids B2 (1990) 745.

49. Rewoldt, G., Phys. Fluids $\underline{31}$ (1988) 3727.

50. Spong, D.A., Sigmar, D.J., and Ramos, J.J., Fusion Technol. 13 (1988) 428.

51. Itoh, S.I., Itoh, K., Tuda, T., and Tokuda, S., J. Phys. Soc. Jpn $\underline{51}$ (1982) 304.

52. Spong, D.A., Holmes, J.A., and Lebouf, J.-N., Christenson, Proc. IAEA Tech. Committee Meeting on Alpha Particles in Fusion Research, Kiev (1989) [Fusion Technol. 18, \#3, Nov. 1990].

53. Van Dam, J.W., Fu, G.Y., and Cheng, C.Z., Proc. IAEA Tech. Committee Meeting on Alpha Particles in Fusion Research, Kiev (1989) [Fusion Technol. 18, \#3, Nov. 1990].

54. Sigmar, D.J., Hsu, C.T., White, R.B., and Cheng, C.Z., Proc. IAEA Tech. Committee Meeting on Alpha Particles in Fusion Research, Kiev 
(1989). Also, Massachusetts Institute of Technology Report PFC/JA-89-58.

55. Cheng, C.Z. and Chance, M.S., Phys. Fluids $\underline{29}$ (1986) 3695.

56. Fu, G.Y. and Van Dam, J.W., Phys. Fluids B 1 (1989) 1949.

57. Cheng, C.Z., Phys. Fluids B 2 (1990) 1427.

58. Chen, L., "On Resonant Excitations of High-n Magnetohydrodynamic Modes by Energetic/Alpha Particles in Tokamaks," Princeton Plasma Physics Laboratory Report PPPL-2597 (1989).

59. Anderson, D. and Lisak, M., Phys. Fluids 27 (1984) 4.

60. Bickerton, R., et al., Plasma Phys. Controlled Nuclear Fusion Research (Nice, France) I (1989) 41.

61. Start, D.F.H., Bhatnagar, V.P., Boyd, D.A. et al., Proc. IAEA Tech. Committee Meeting on Alpha Particles in Fusion Research, Kiev (1989) [Fusion Technol., 18, \#3, Nov. 1990].

62. Heidbrink, W., (General Atomics) private communication (1990).

63. Wong, K.-L., (Princeton Plasma Physics Laboratory) private communication (1990).

64. Houlberg, W.A., Attenberger, S.E., and Hively, L.M., Nucl. Fusion $\underline{22}$ (1982) 935.

65. Uckan, N.A., Sheffield, J., and Selcow, E.C., "A Simple Contour Analysis of Ignition Conditions and Plasma Operating Regimes in Tokamaks," Proc. 11th Symp. on Fusion Engineering (Austin, Texas, 18-22 Nov. 1985) 350.

66. Troyon, F., Gruber, R., Sauremann, H., Sementazo, S., and Suci, S., Plasma Phys. $\underline{26}$ (1984) 209; and Troyon, F., Gruber, R., Phys. Letters 110A (1985) 29. 
67. Murakami, M., Callen, J., and Berry, L., Nucl. Fusion 16 (1976) 347; and Greenwald, M., Terry, J., Wolfe, S., Ejima, S., Bell, M., Kaye, S., and Neilson, G., Nucl. Fusion 28 (1988) 2199.

68. Cordey, J., in "Basic Physical Processes of Toroidal Fusion Plasmas," Vol. 1, Proceedings of a Workshop, Varenna, 1985. EUR 10418 EN. Citta di Castello, Italy: Monotypia Franchi; Luxembourg: Office for Official Publications of the European Com nunities, 1986, p. .

69. Sager, G.T., Tokamak Burn Control, U.S. Department of Energy Report DOE/ER/521277-36 (June, 1988).

70. Tani, K., Takizuka, T., Azumi, M., and Yamagiwa, M., Plasma Phys. Controlled Nuclear Fusion Research (Nice, France) 2 (1989) 121.

71. Borrass, K., "Burn Temperature Control and Stabilization of Thermal Runaway in Tokamaks," EUR. FU. XII 80/86/61 (1986).

72. Okamoto, M. and Ohnishi, M., J. Nucl. Sci. Technol (Atomic Energy Society of Japan) $\underline{20}$ (1983) 366 .

73. Bromberg, L., Fisher, J.L., and Cohn, D.R., Nucl. Fusion 20 (1980) 203.

74. Kikuchi, M., Azumi, M., Tsuji, S., Tani, K., and Kubo, H., Nucl. Fusion $\underline{30}$ (1990) 343.

75. VonGoeler, S., Stodiek, W., and Sauthoff, N., Phys. Rev. Lett. $\underline{33}$ (1984) 1201.

76. Stotler, D., Post, D., and Bateman, G., Fusion Technol. 14 (1988) 1304.

77. Yamagiwa, M., Kimura, H., and Takizuka, T., Nucl. Fusion $\underline{29}$ (1989) 1799.

78. "ITER Conceptual Design Interim Report," IAEA, Vienna, Austria, 1989.

79. Goldston, R.J., Plasma Phys. Controlled Fusion 26 (1984) 87. 
80. Lackner, K., "Physical Equivalence of Tokamak Discharges" Comments on Plasma Physics and Controlled Fusion XIII (1990) 163.

81. Holdren, J.P., Berwald, D.H., Budnitz, R. J., et al., "Report of the Senior Committee on Environmental, Safety and Economic Aspects of Magnetic Fusion Energy," Lawrence Livermore National Laboratory Report UCRL-53766 (June 1989). 


\section{Figure Captions}

Fig. 1 The Lawson and ignition conditions for the D-T and D-D cycles, assuming $Z=1$ in a zero-dimensional model (from Ref. 6).

Fig. 2 The reaction parameter $\left\langle\sigma \mathrm{Vi}_{1}>\mathrm{T}_{1}^{2}\right.$ as a function of ion temperature for several fusion fuel cycles (from Ref. 6).

Fig. 3A $\quad \beta_{\alpha} / \beta_{\text {th }}$ and $n_{\alpha} / n_{e}$ vs. temperature for $Z_{e f f}=1$ and $Z_{e f f}=2$.

Fig. 4 The fraction of the D-D neutron rate due to thermal reactions, beam-thermal (target) reactions and beam-beam reactions for TFTR super shots. For comparison, the high performance JET point (circles) is shown.

Fig. 5 Characteristic alpha-plasma-physics parameters.

For the profiles $T=T(0)\left(1-r^{2} / a^{2}\right)$ and $n=n(0)\left(1-r^{2} / a^{2}\right)^{1 / 2}$, where $r$ is radial distance from the magnetic axis in the equatorial plane, volume-averaged quantities are given by $\langle\mathrm{T}\rangle=1 / 2 \mathrm{~T}(0),\langle\mathrm{n}\rangle=(2 / 3) \mathrm{n}(0)$ and $\left\langle\beta_{\mathrm{th}}\right\rangle=(2 / 5) \beta_{\mathrm{th}}(0)$. When $\mathrm{T}(0) \geqslant 20 \mathrm{keV}$, we have $\left\langle\mathrm{p} \alpha^{*}\right\rangle \sim 0.3 \mathrm{p} \alpha(0)$, and a total power of $\mathrm{P}_{\mathrm{f}} \sim 50 \mathrm{~m}^{3} \mathrm{P} \alpha^{*}(0)$ for CIT parameters. [From Ref. 14].

Fig. 6 Fusion power density for thermal D-T plasmas with a carbon impurity level of $Z_{\text {eff }}=1.5$. [From Ref. 14].

Fig. 7 Contours of constant auxiliary heating power required to maintain the plasma in thermal equilibrium are shown. The conditions assumed for this plot are a plasma current of $11 \mathrm{MA}$, a toroidal field of $10 \mathrm{~T}$ and twice Kaye-All-Complex L-Mode 
confinement. Also shown are the Troyon beta limit and the Hugill-Murakami density limit.

Fig. 8 Comparison of measured (horizontal scale) and calculated (vertical scale) triton burnup from JET.29 The good agreement (to within $\pm 20 \%$ ) implies that almost complete triton confinement is obtained under these conditions.

Fig. 9 Comparison of measured ("x") and calculated escaping triton flux vs. plasma current to a detector at the bottom of TFTR. 33 The good agreement (given the normalization at $0.8 \mathrm{MA}$ ) implies that nearly complete triton confinement would be obtained for reactor-level plasma currents $(\approx 20 \mathrm{MA})$, assuming the loss at other locations behaves similarly.

Fig. 10 Example of MHD-induced losses of $1-\mathrm{MeV}$ tritons in TFTR. The level of escaping tritons increases by a factor of 5-10, inphase with magnetic perturbations $B_{p}$ that are associated with MHD modes. Meanwhile, the triton source term (proportional to the neutron flux) does not fluctuate.

Fig. 11 Approximate thresholds for high-n ballooning, fishbone, and Toroidal Alfven Eigenmodes (TAE) for CIT, TFTR, and ITER machine parameters. The fishbone mode has the potential to eject alpha particles from the plasma, while the MHD ballooning mode has the potential to lower the stable plasma $\beta$-limit. The TAE mode analyses are obtained from local stability analyses, evaluated at the $q=1.5$ surface, assuming $\mathrm{T}_{\mathrm{e}}=10 \mathrm{keV}$. (Global stability analyses can give local $\beta_{\alpha}$ thresholds higher by factors of 5-10) .53,57 The circles represent projected central $\beta_{\alpha}$ for DT experiments (see Table 2). 
Fig. 12 Linear growth rates $\gamma$ (in units of $10^{5} \mathrm{sec}^{-1}$ ) from a fully kinetic calculation vs. local $\beta \propto \mathrm{n}_{e}$ (for fixed $\mathrm{T}_{e}, \mathrm{~T}_{\mathrm{i}}$ and $\mathrm{B}_{\mathrm{o}}$ ) for a CIT $\left(R_{O}=1.75 \mathrm{~m}\right.$ design). 49 The $\beta$-limit is significantly reduced by the presence of the alpha population, but the trapped-electron drift mode is essentially unaffected by the alphas.

Fig. 13 Estimated plasma diffusion rate $\mathrm{D} \sim \gamma / \mathrm{k}_{\perp} 2$ associated with the presence of alpha particles, as calculated from the linear kinetic theory of ballooning and toroidicity-induced Alfven eigenmodes. 52 The alphas are predicted to produce anomalous diffusion at relatively low $\beta$-values. Diffusion coefficients above the dotted line are expected to effect the alpha-heating efficiency.

Fig. 14 Single-particle orbit in the $r-\theta$ plane for an initially untrapped alpha particle in the presence of a toroidicity-induced Alfven eigenmode.54 Near the center the particle becomes resonant with the wave and looses energy, thereby increasing its radial outward excursion. The spiraling part of the orbit describes the resonant energy loss of a circulating alpha particle. The final conversion to a trapped particle loss-orbit is caused by a non-collisional change of the pitch angle, due to wavescattering.

Fig. 15 Same conditions as Fig. 7 but including the contours of constant Q-value. (Courtesy of Glenn Bateman).

Fig. 16 Same conditions as Fig. 7 but including the contours of constant ignition margin. (Courtesy of Glenn Bateman).

Fig. 17 Same conditions as Fig. 7 but assuming Kaye-All-Complex L-Mode confinement. (Courtesy of Glenn Bateman). 
Fig. 18 Same conditions as Fig. 17 but including the contours of constant Q-value. (Courtesy of Glenn Bateman). 


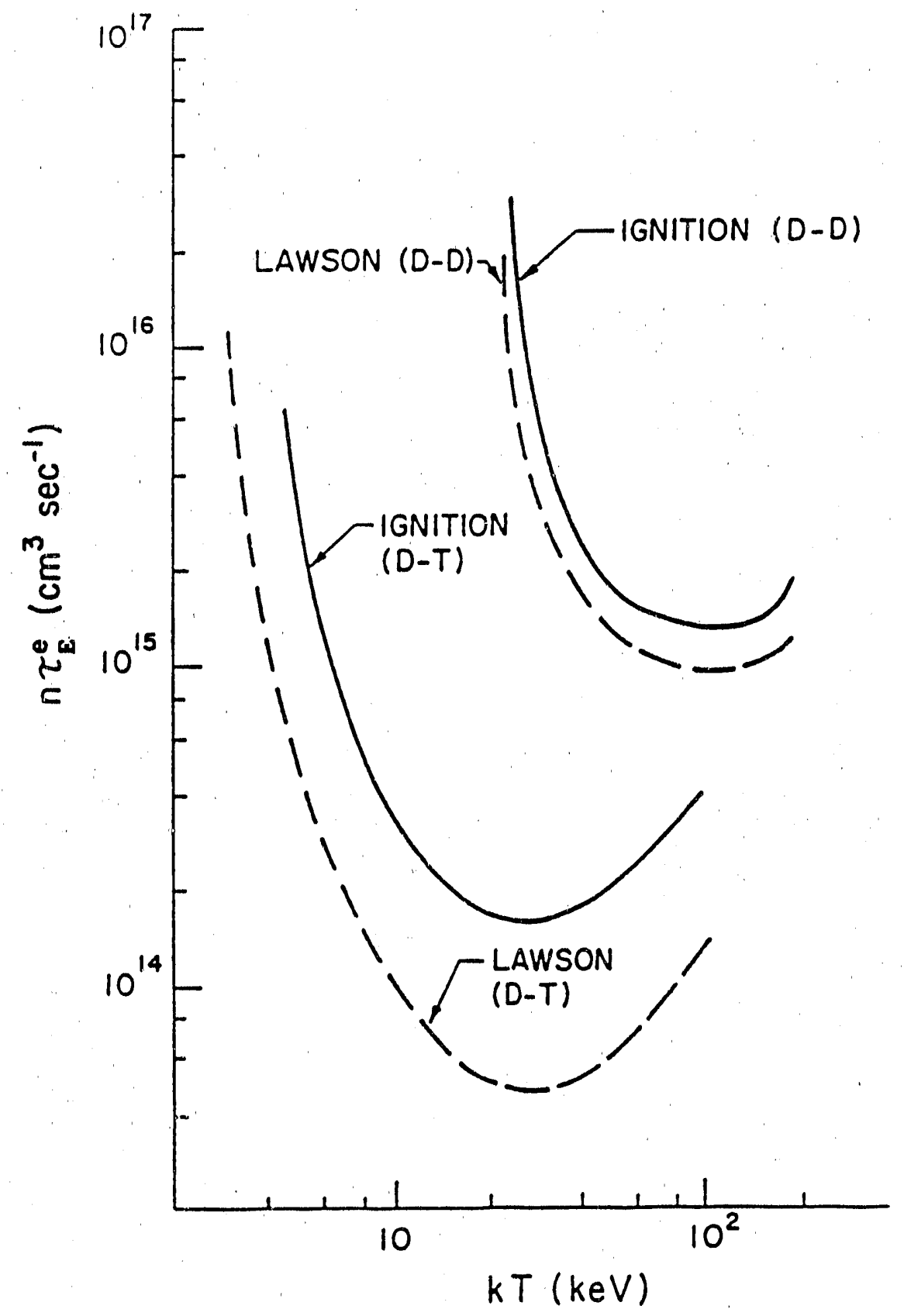

Fig. 1 


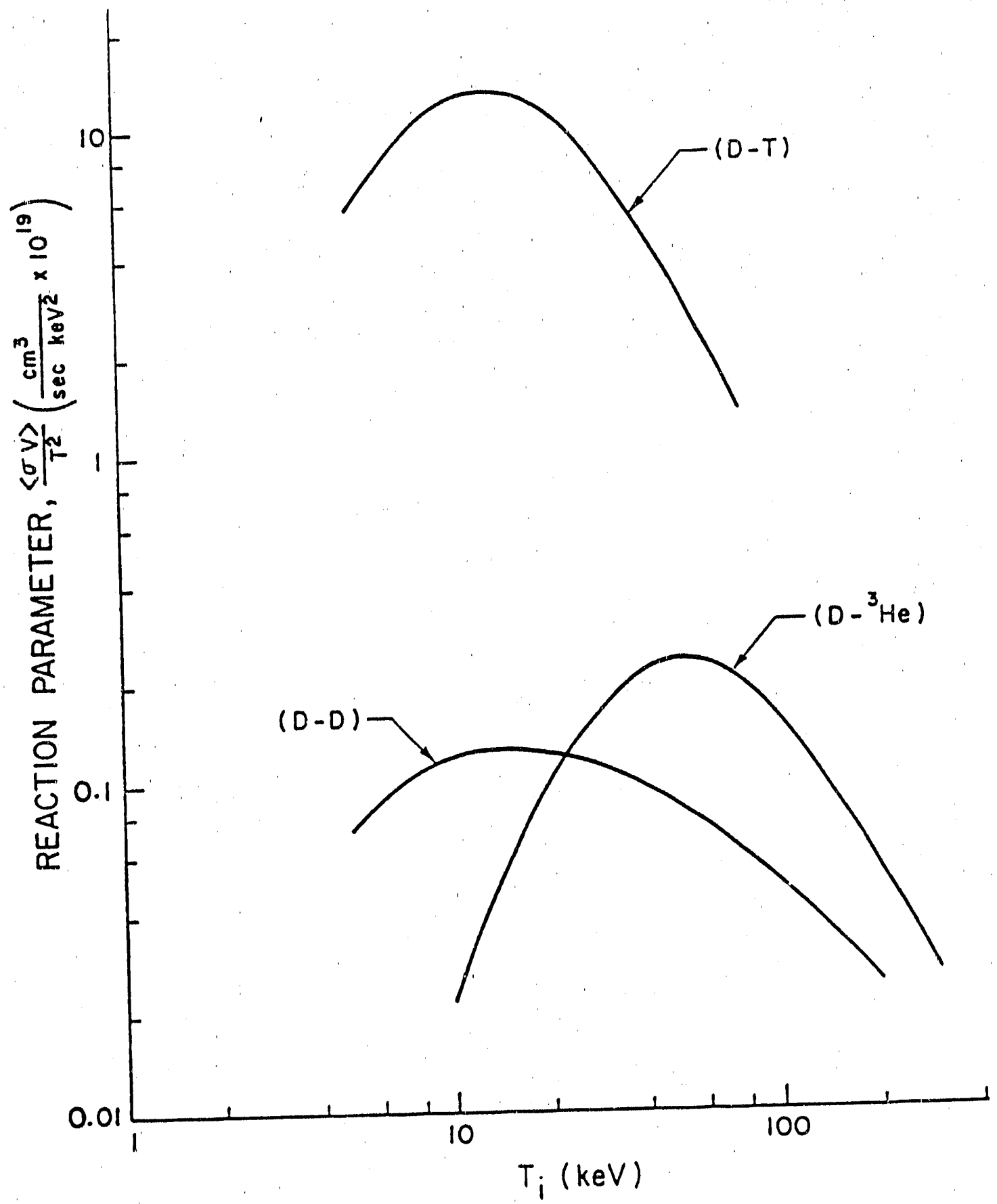

Fig. 2 
PPPL\#90X0355

\section{THERMONUCLEAR 50-50 D-T PLASMA $Z_{\text {eff }}=1$ and 2}

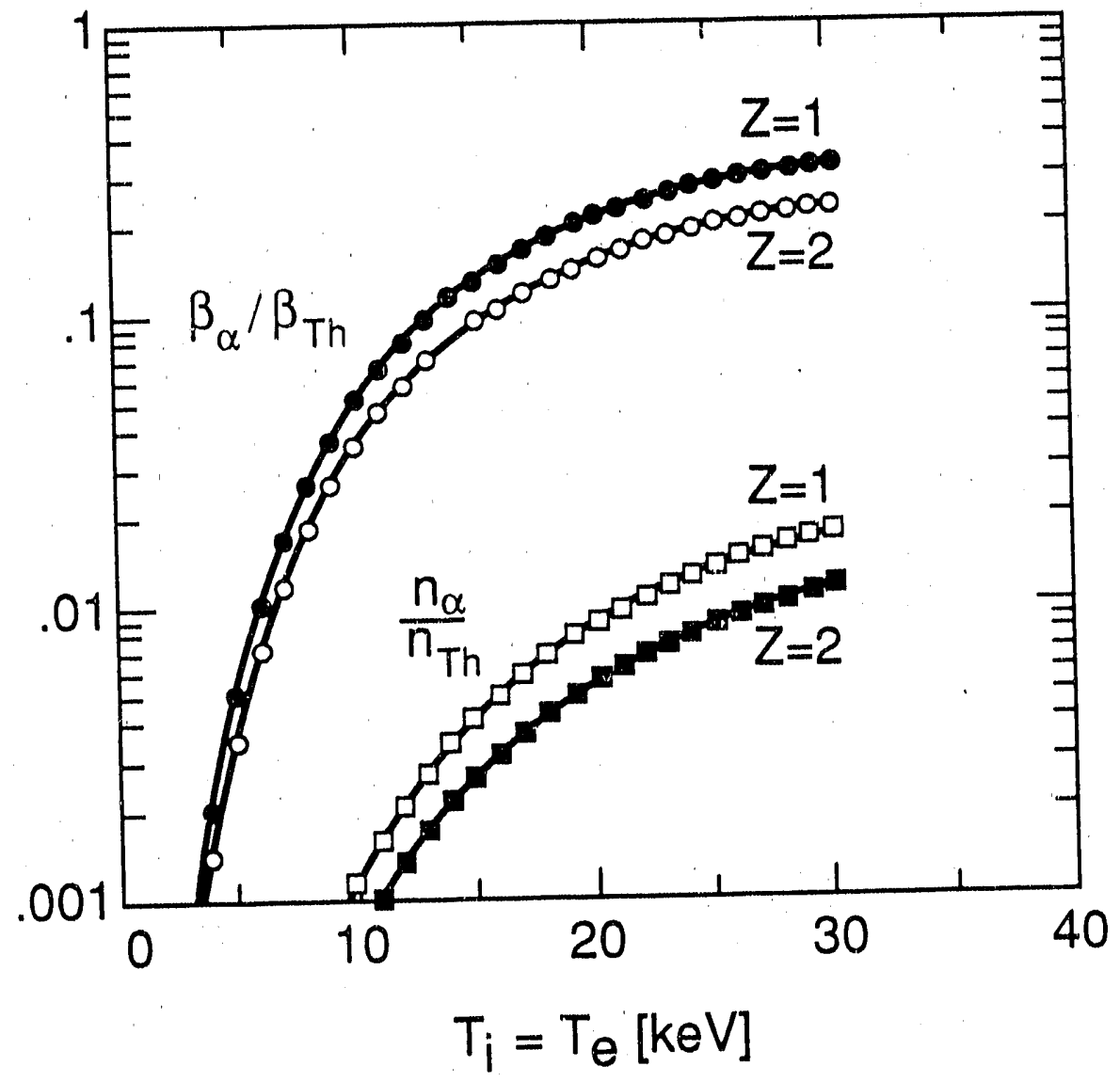

FIG. 3 


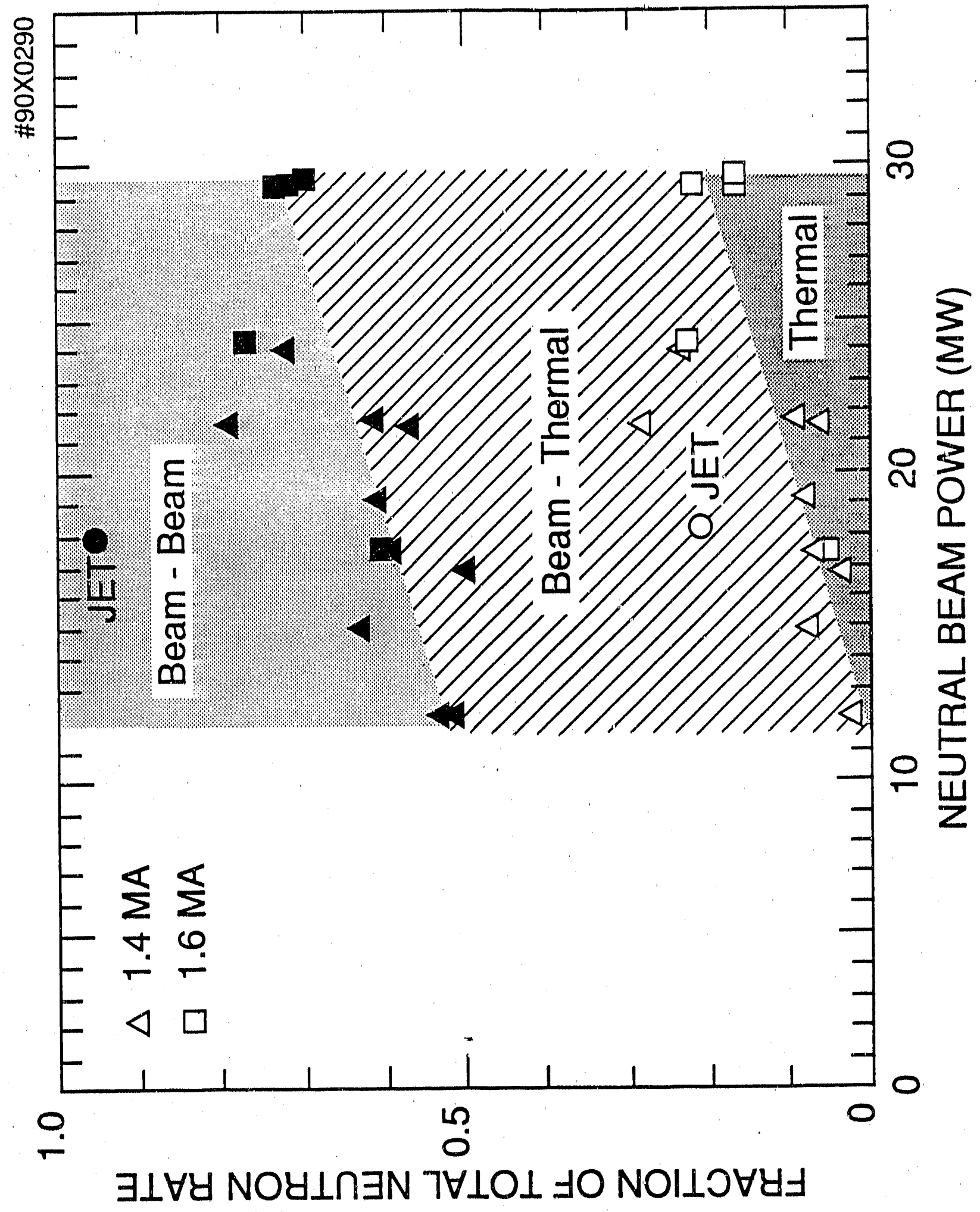

Fig. 4 
UNIVERSAL PLOT OF CHARACTERISTIC

Alpha Plasma-Physics Parameters

$n_{\alpha}(0) / n_{e}(0)$

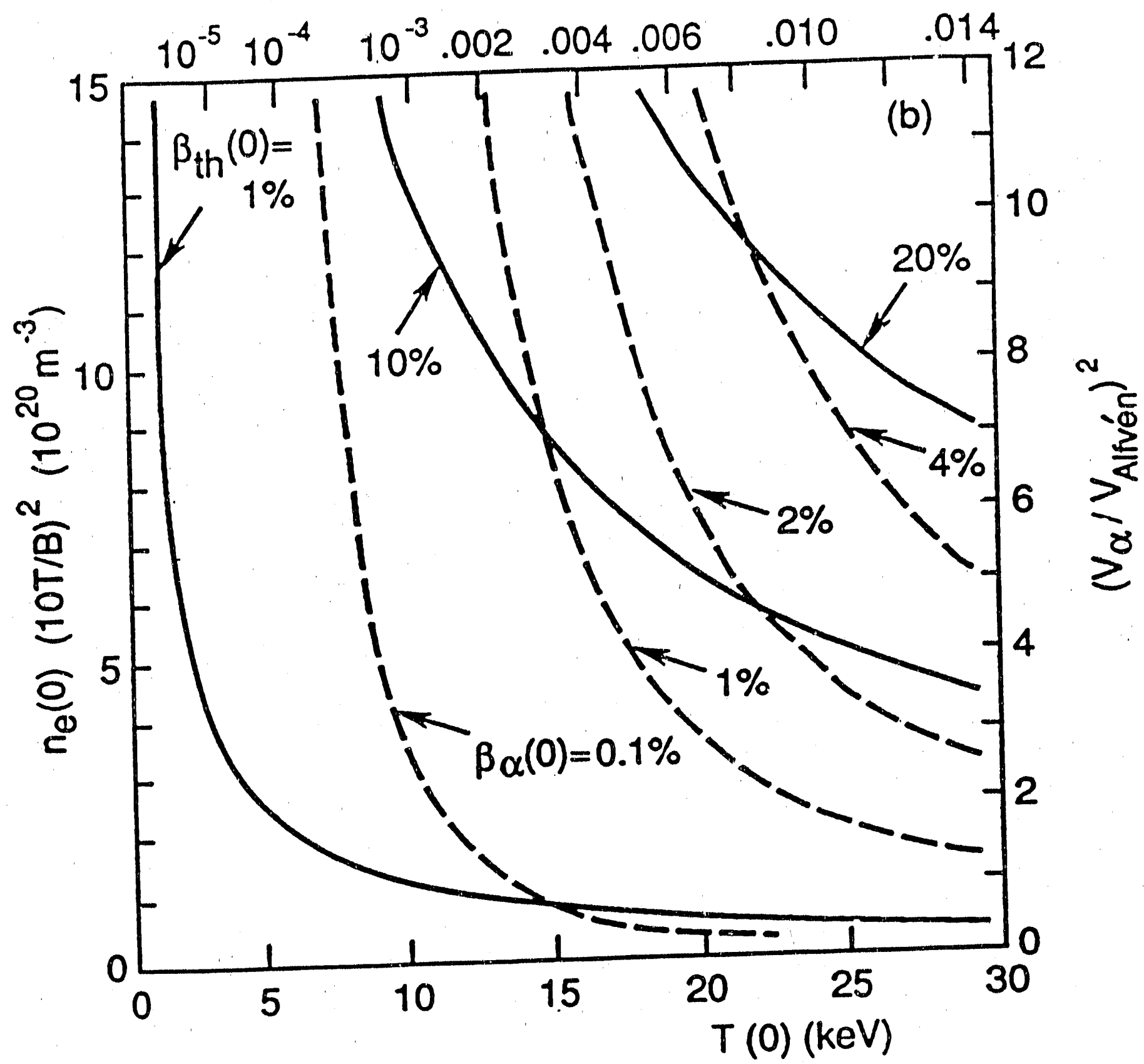

Fig. 5 


\section{Contours of $P_{\alpha}{ }^{*}=P_{\alpha}-P_{\text {BREMS }}$}

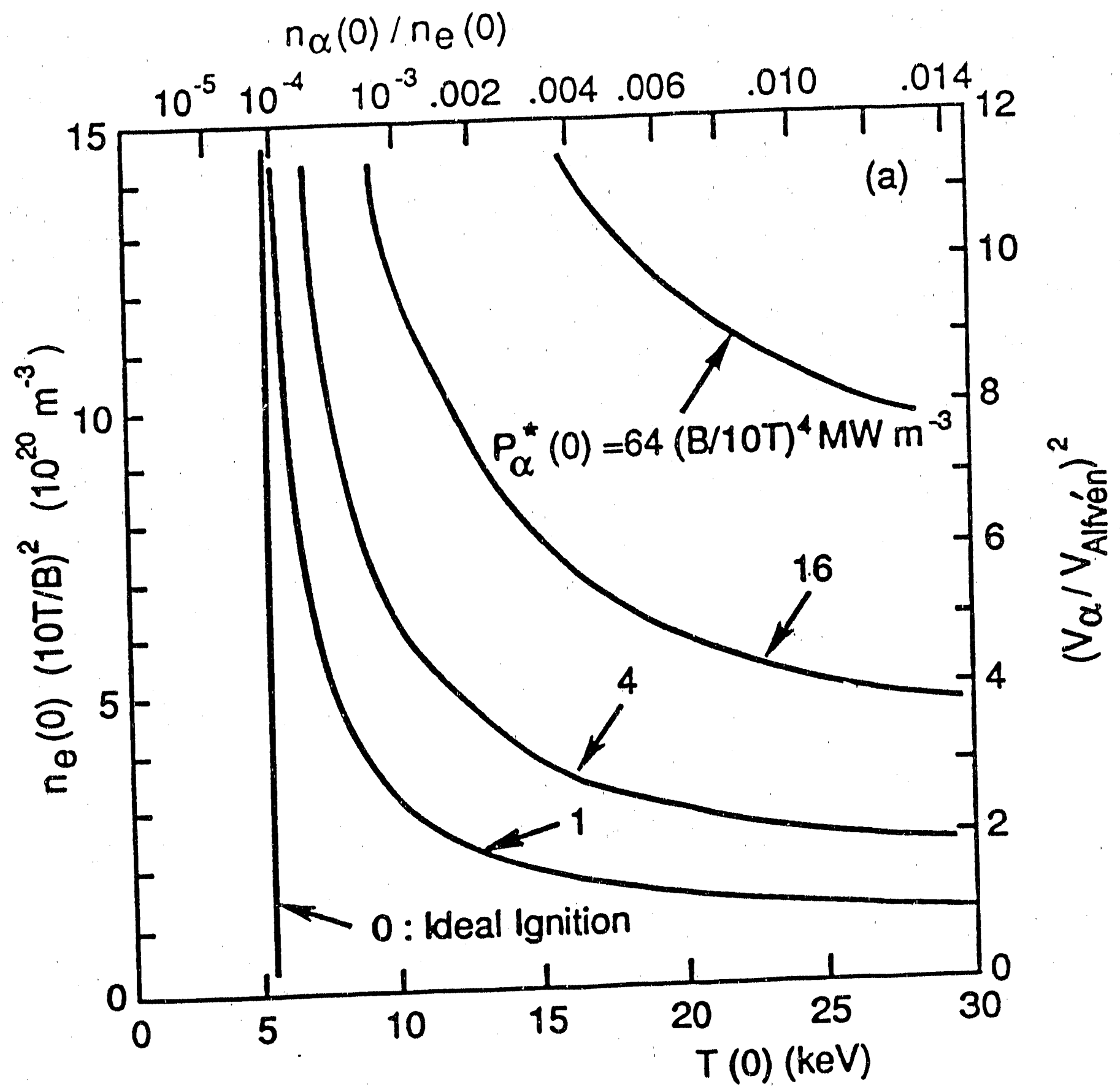


$\# 90 \times 0291$

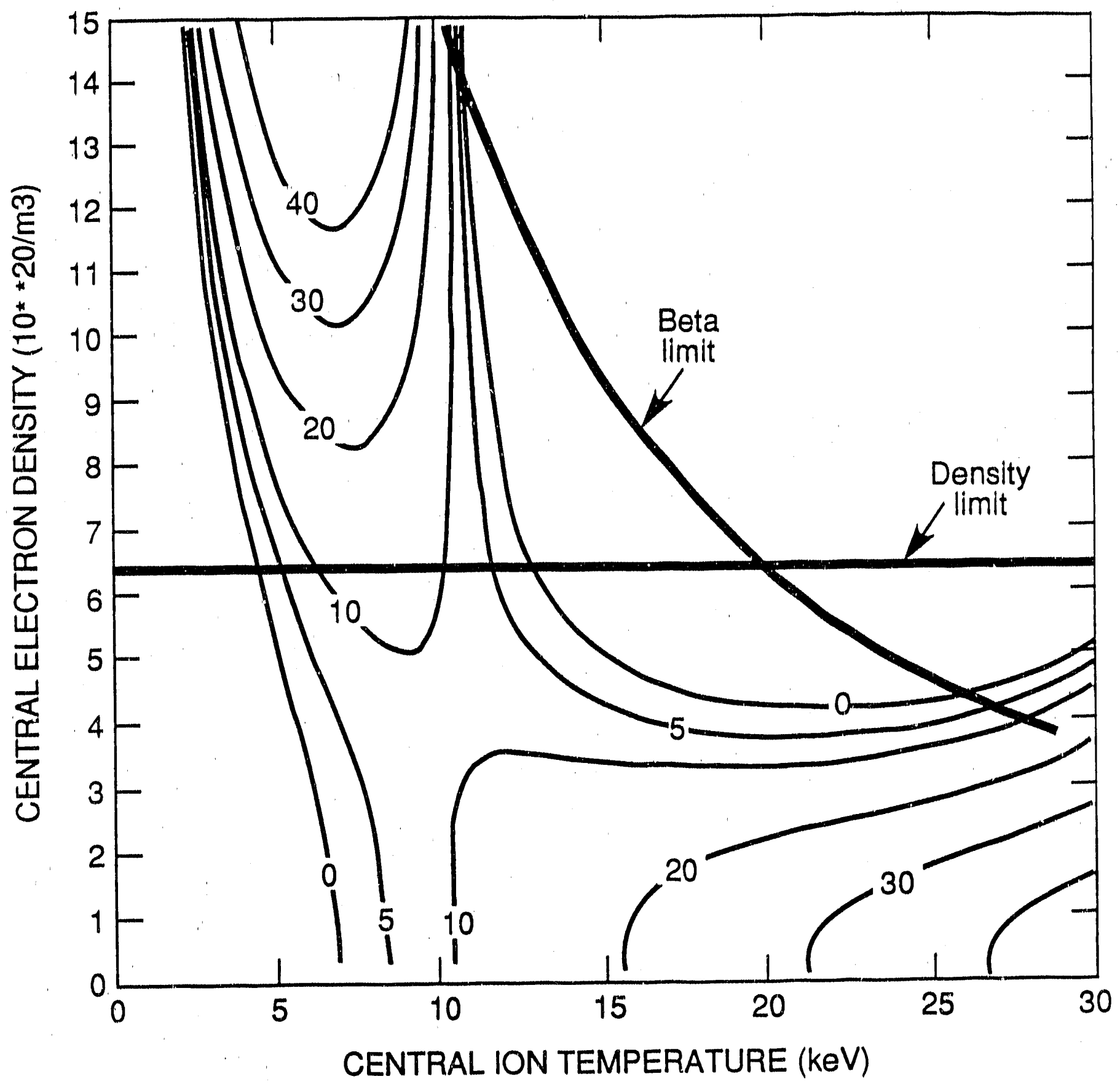




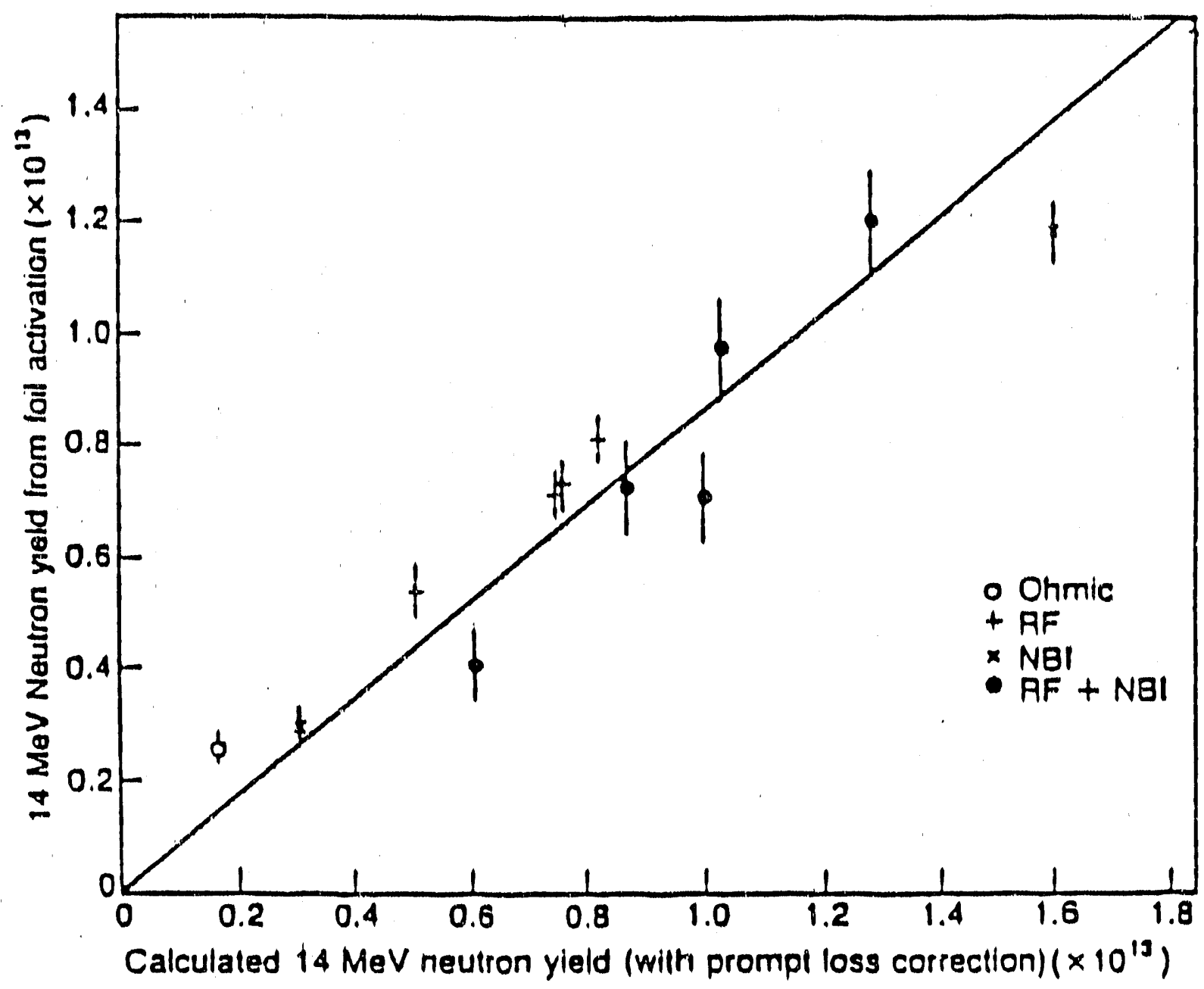

Fig. 8 


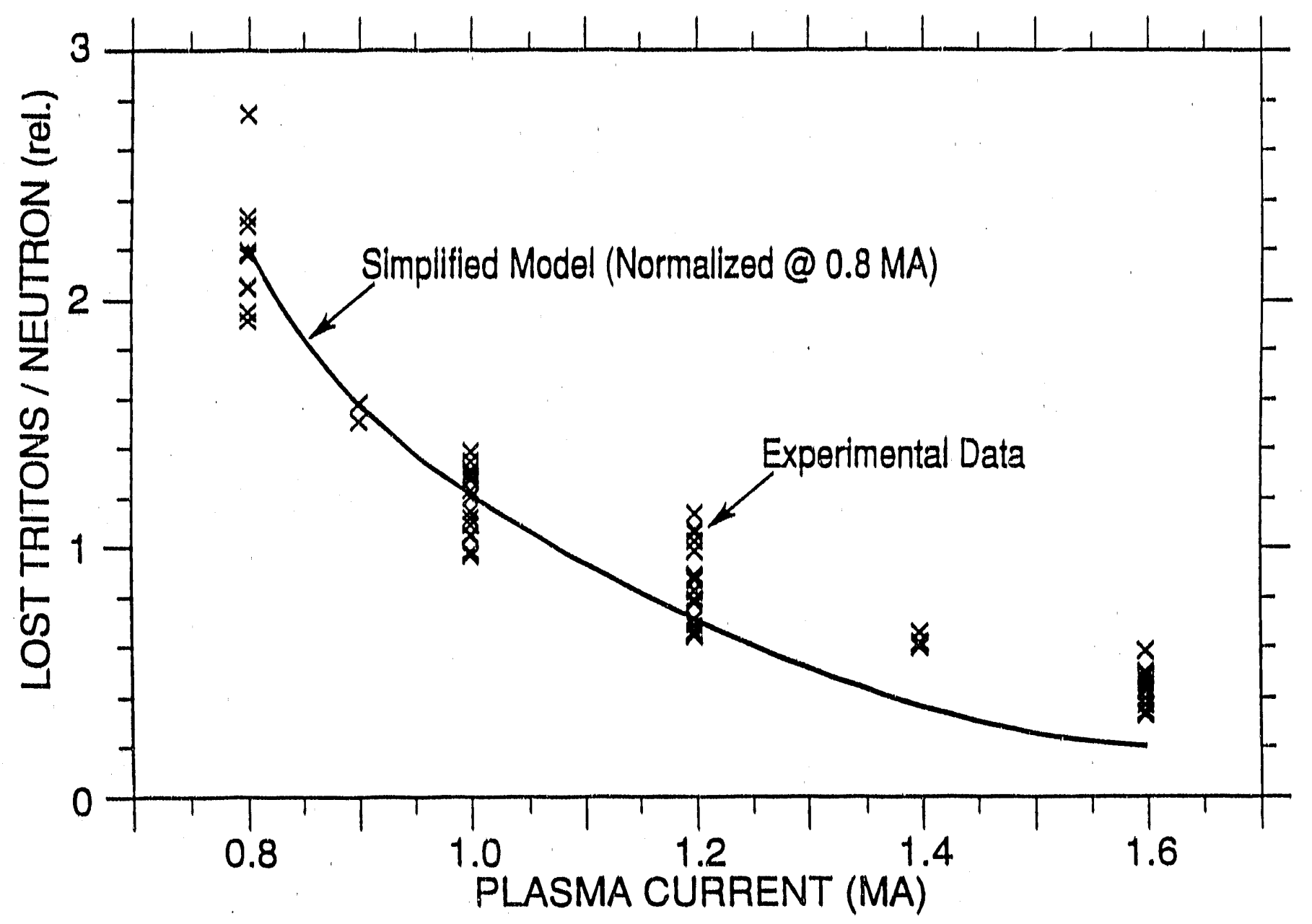


\#88X1052
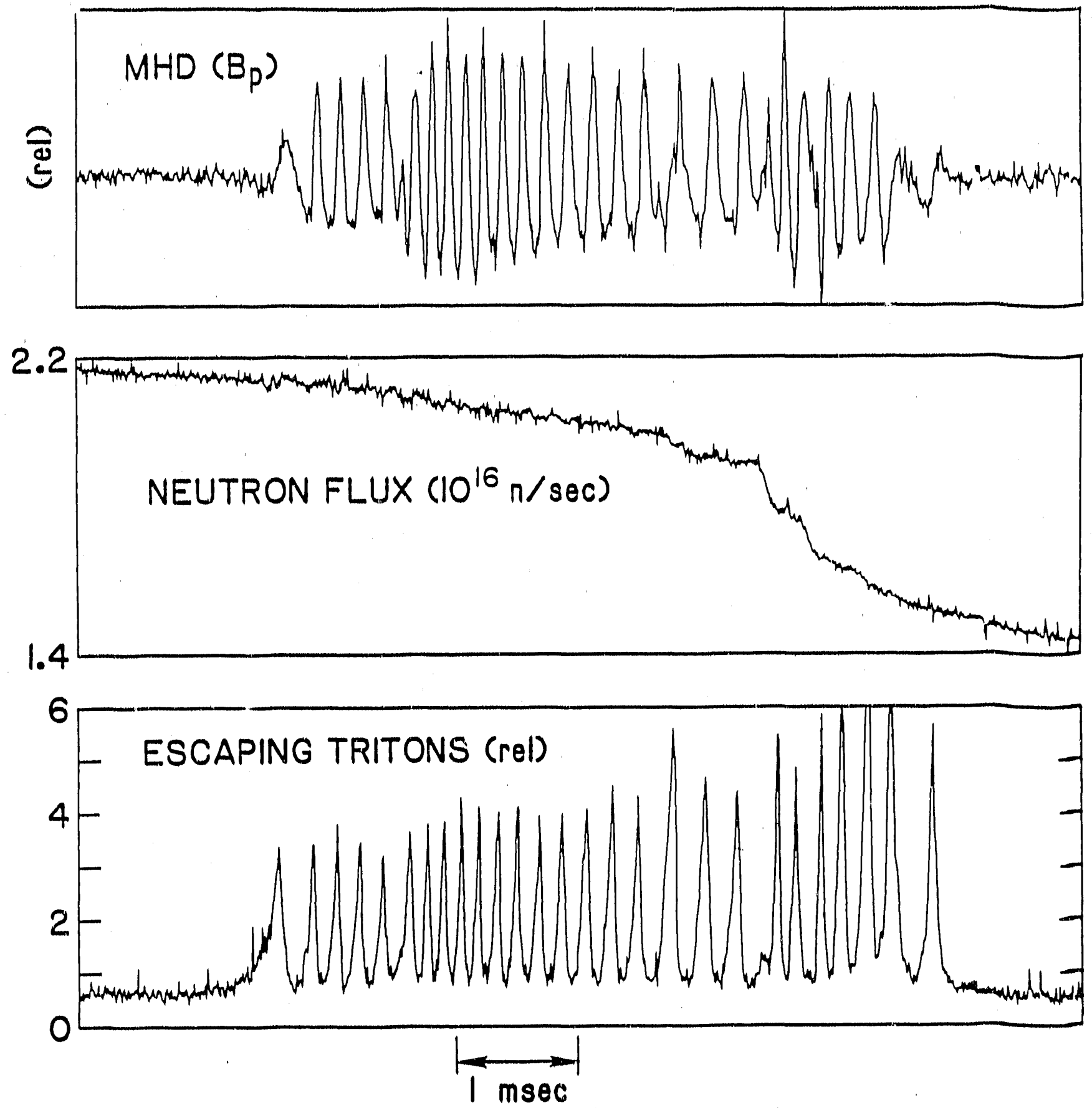


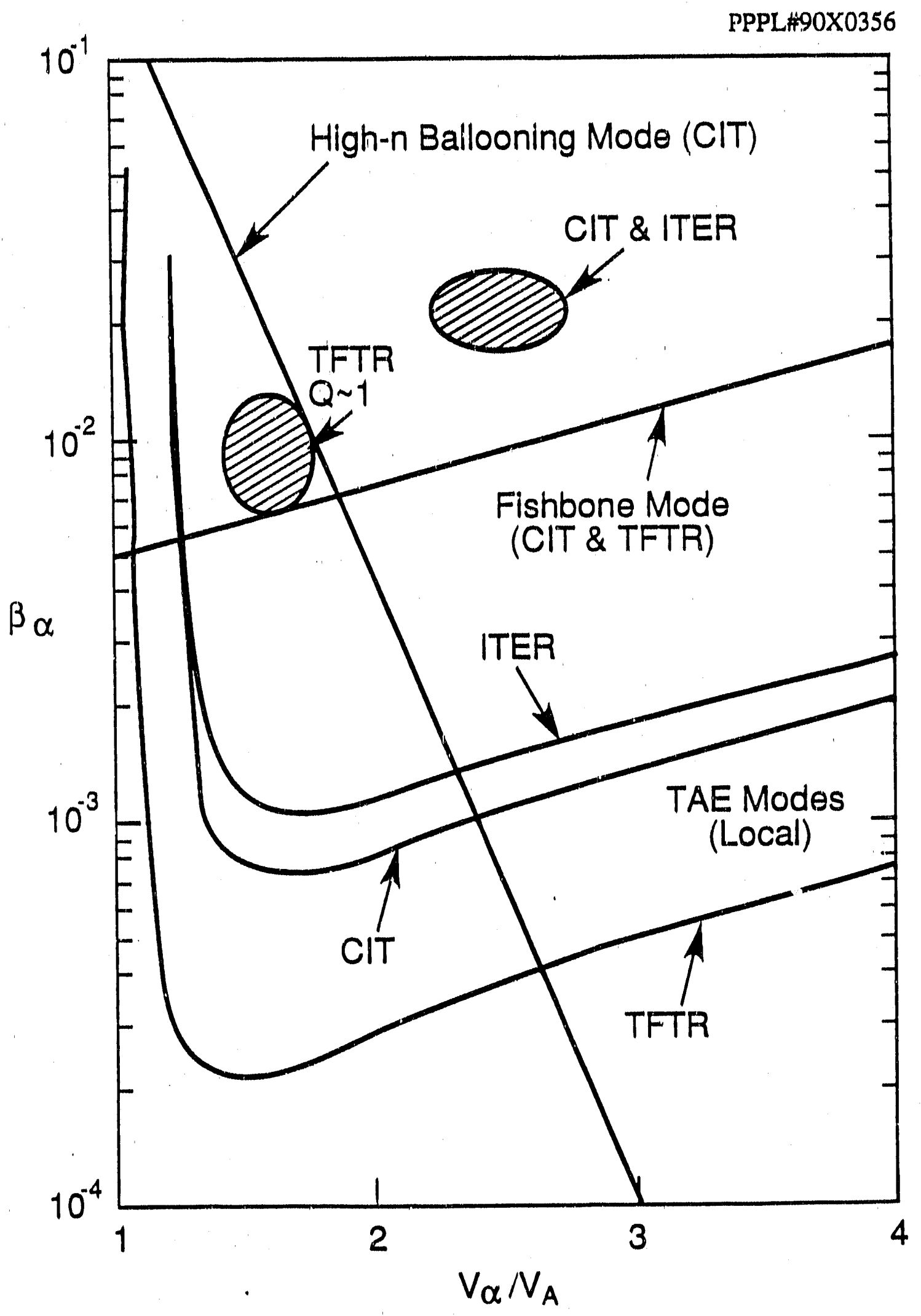

FIg. 11 


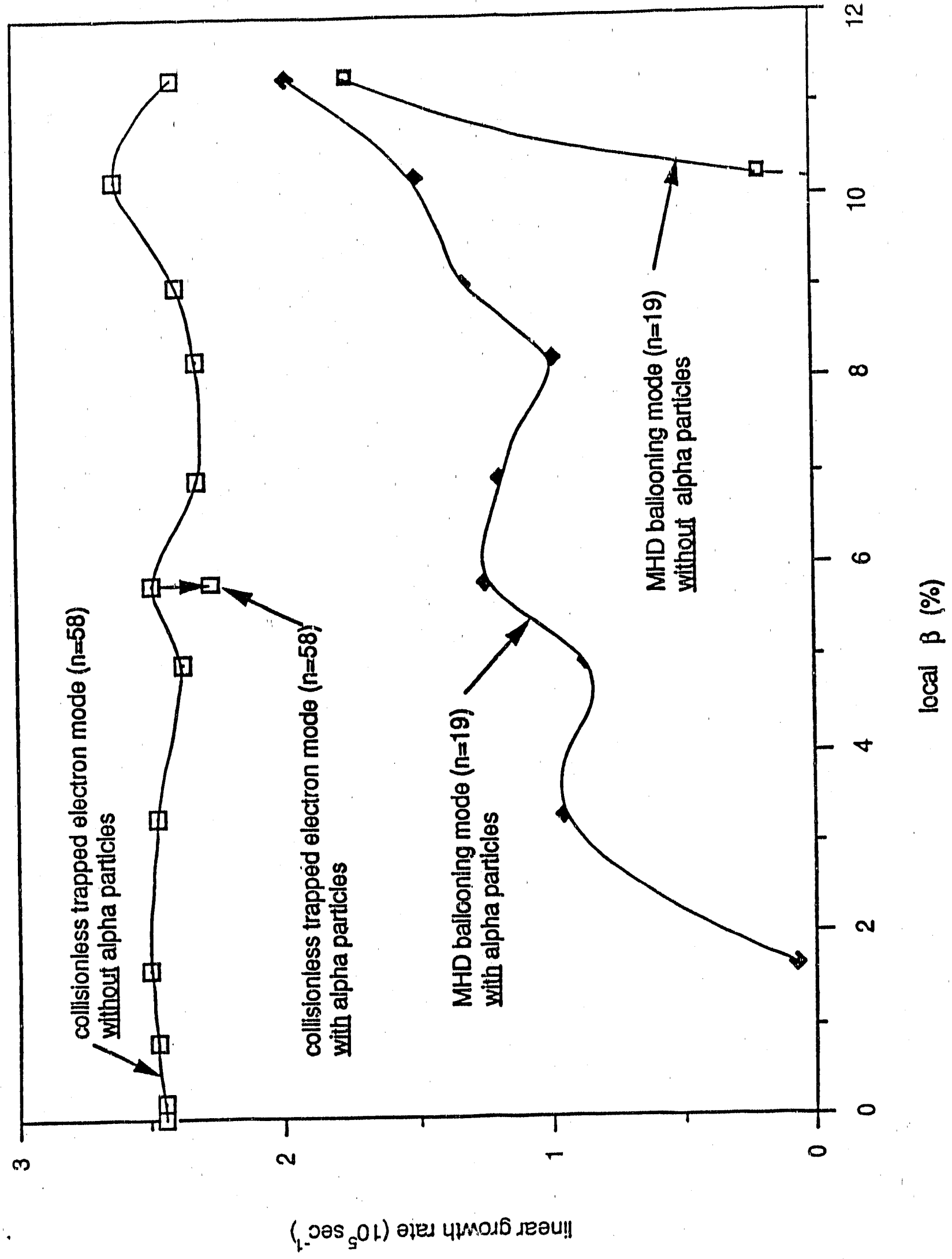

F1g. 12 
$-55-$

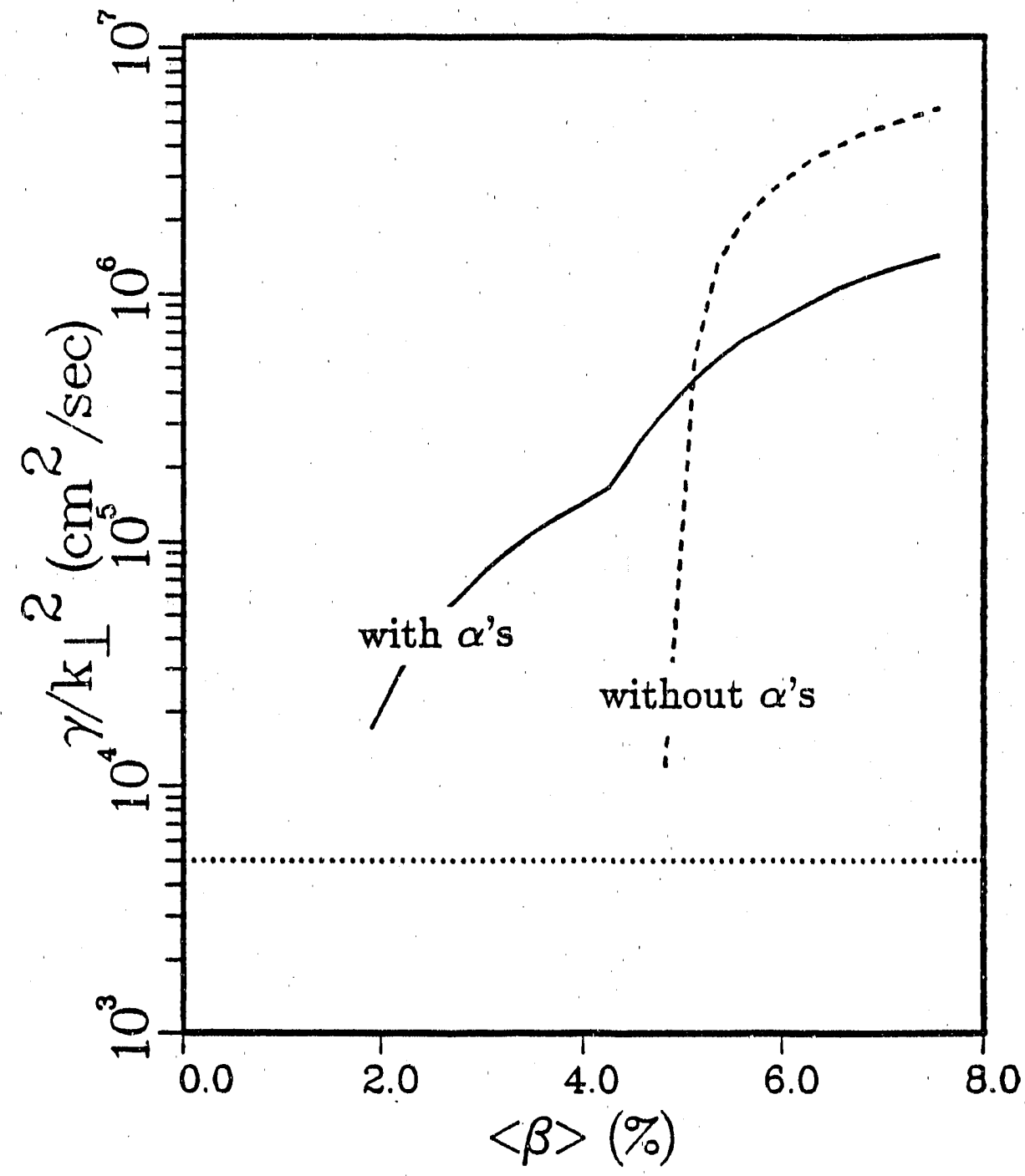

Fig. 13 


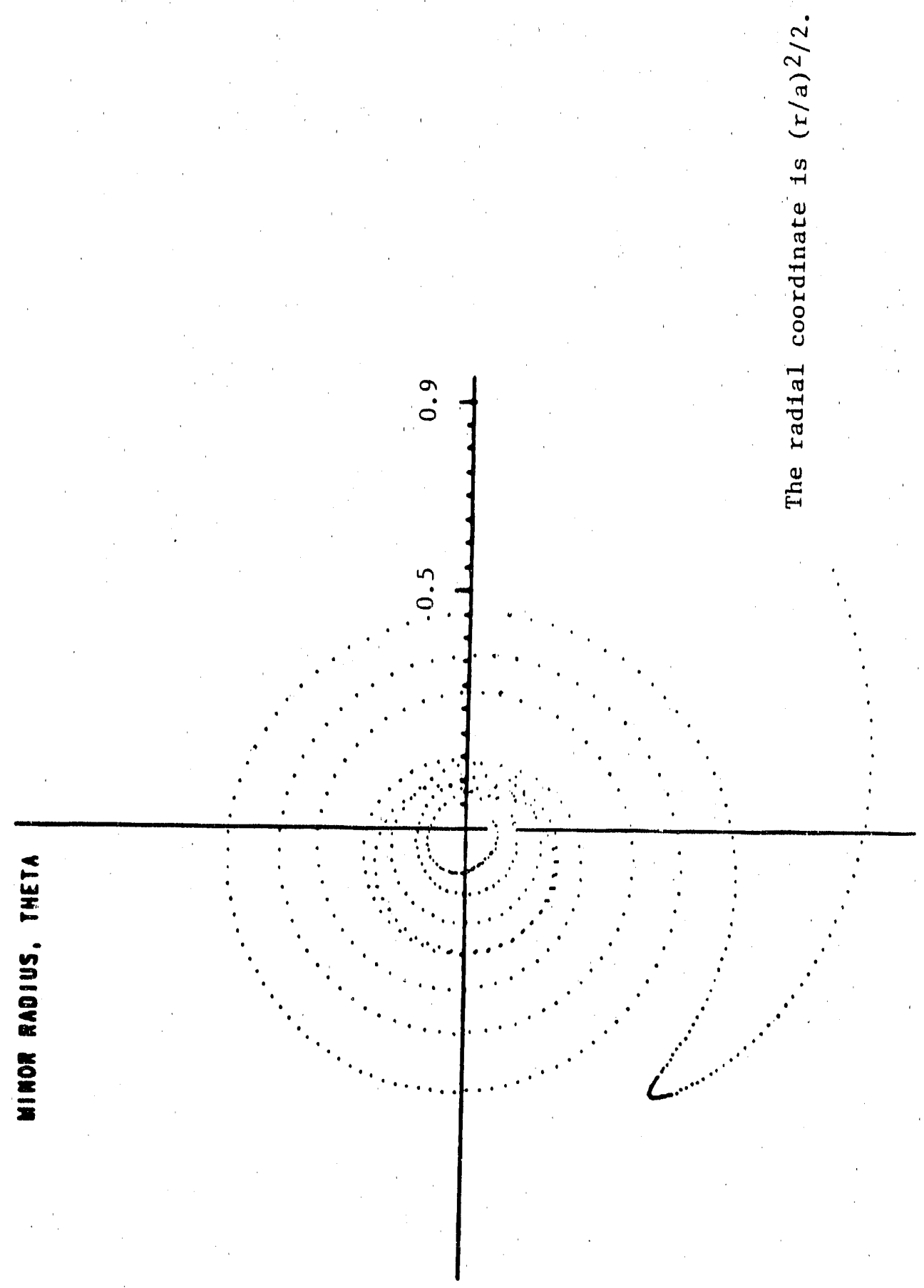

Fig. 14 
\#90X0288

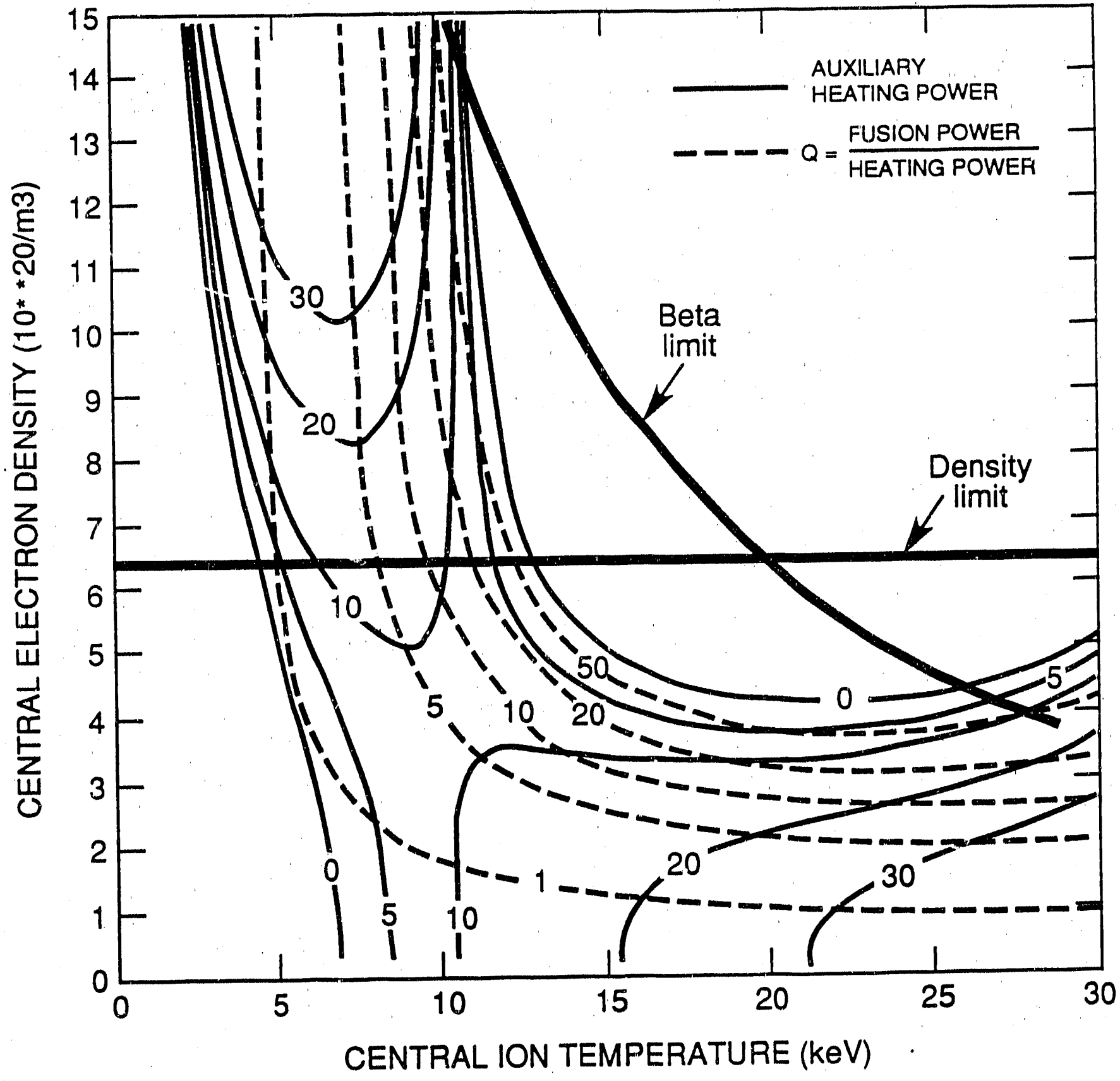

F1g. 15 
$\# 90 \times 0289$

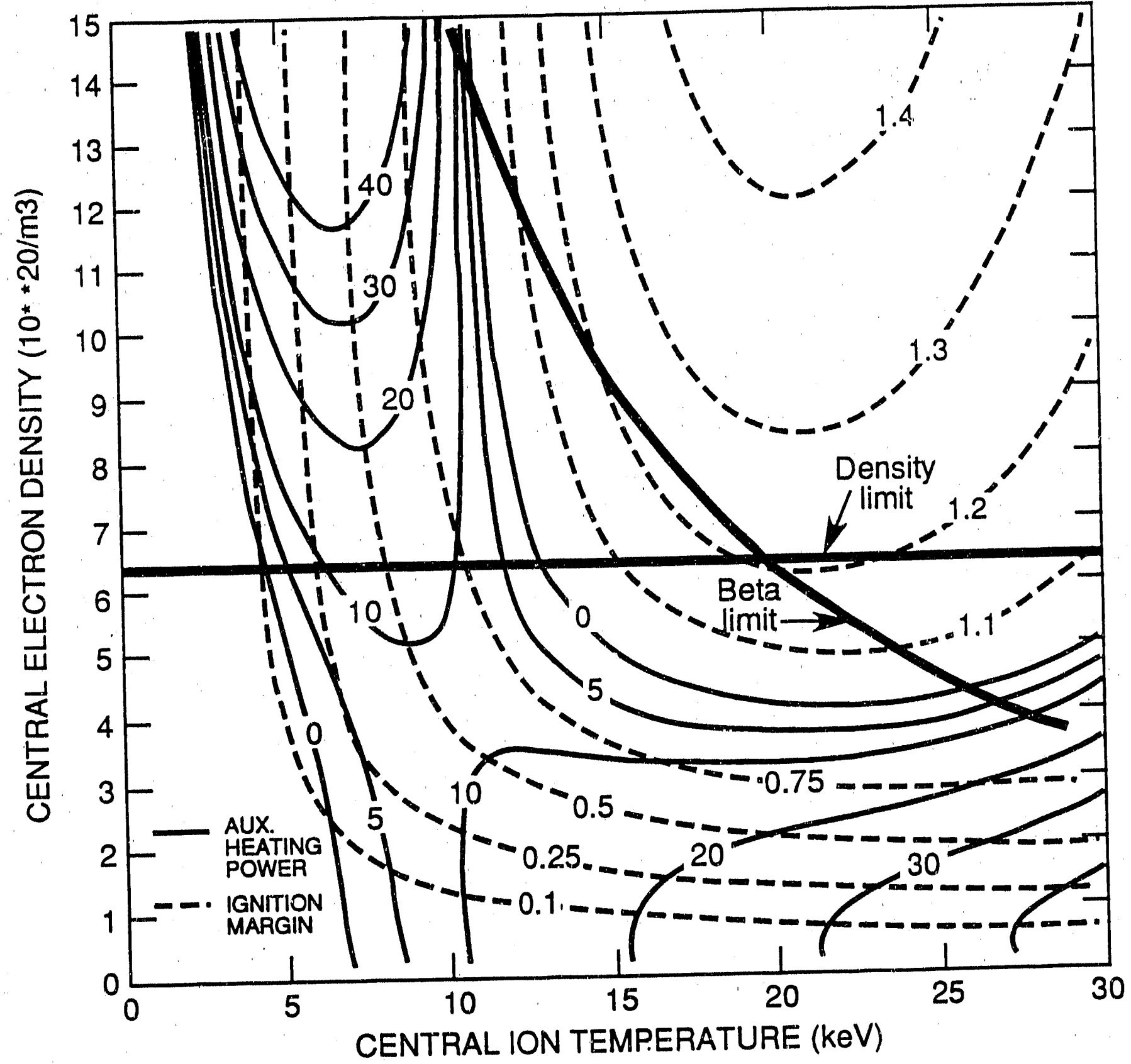


\#90X0110

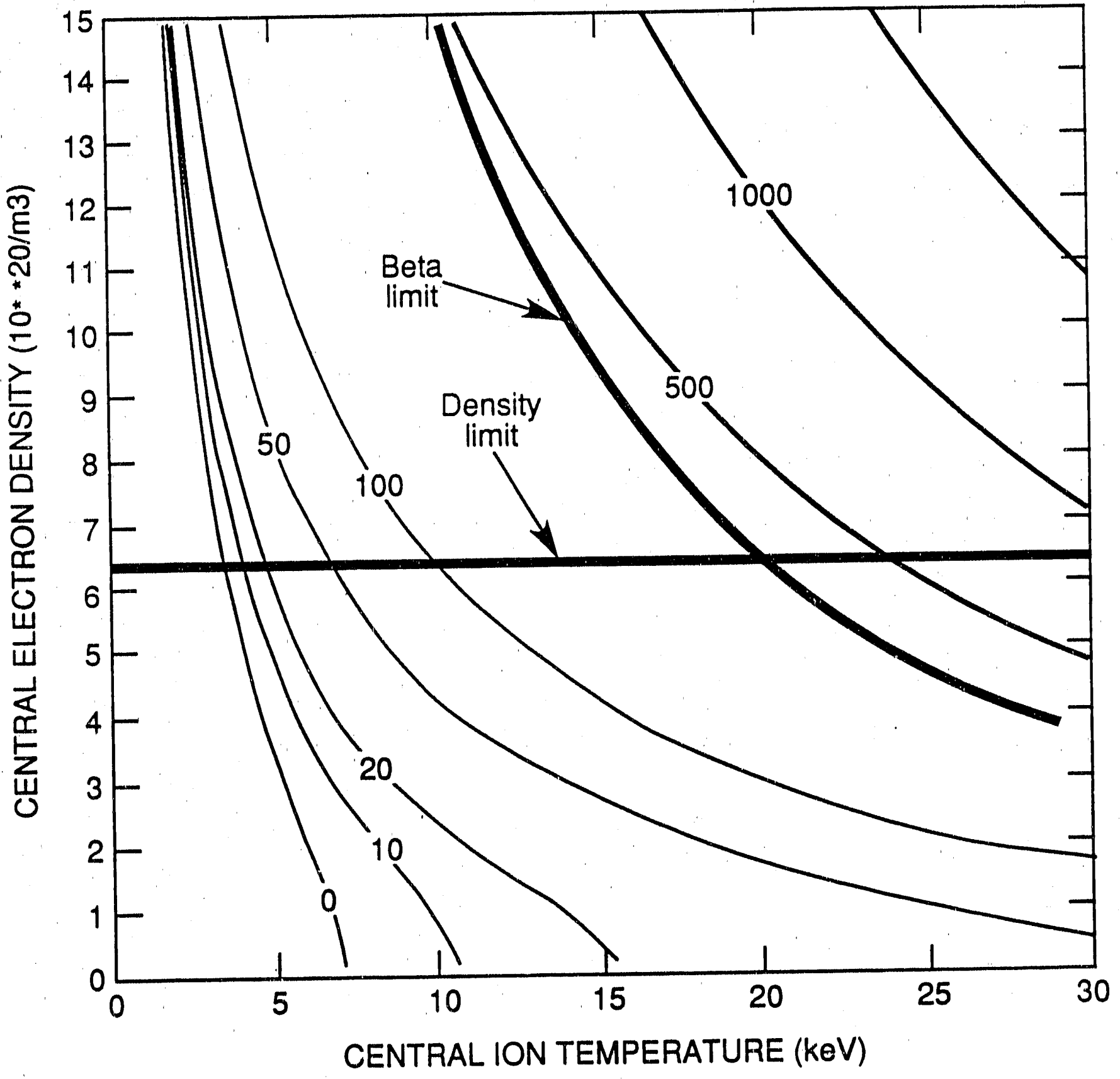




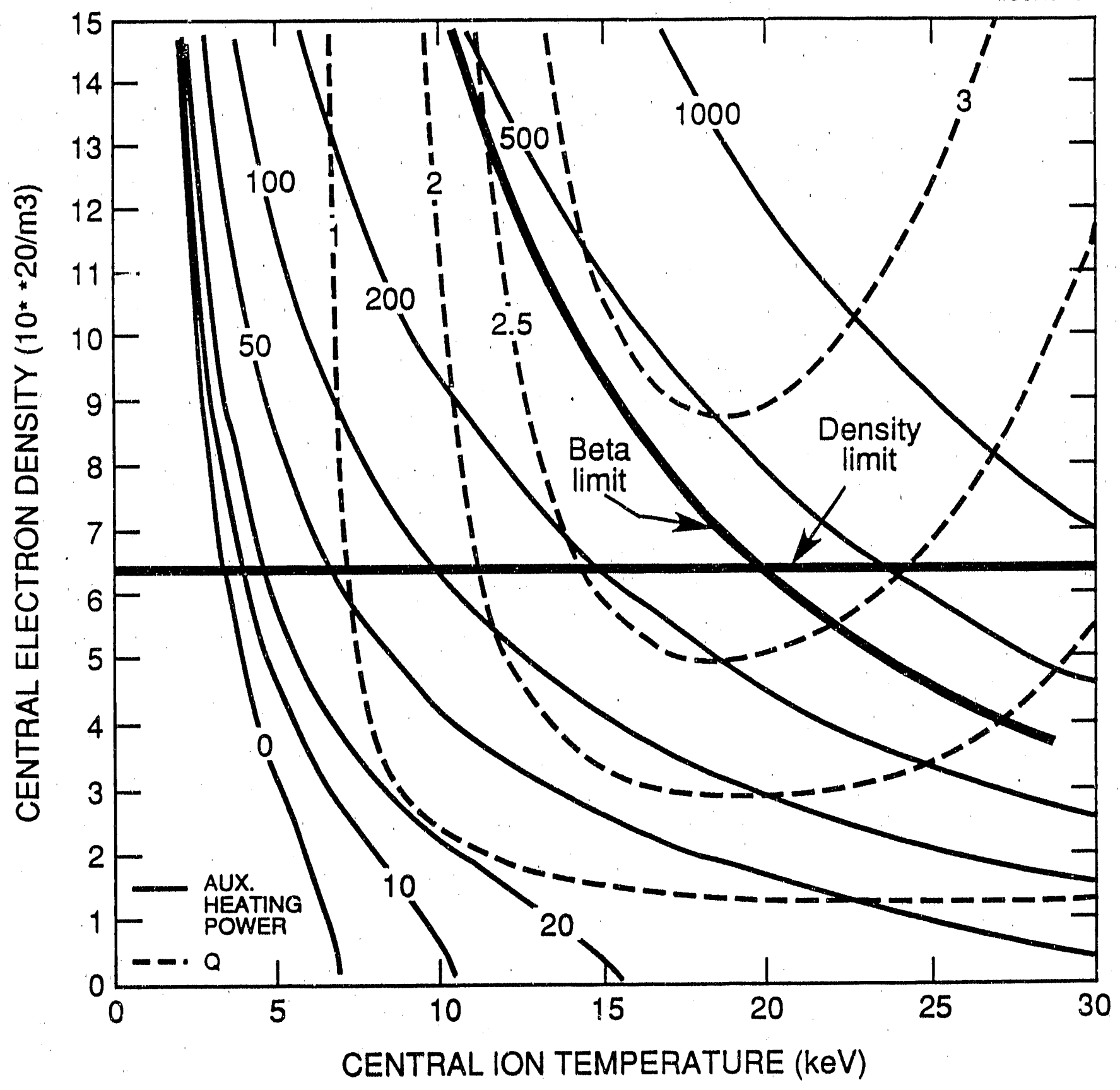



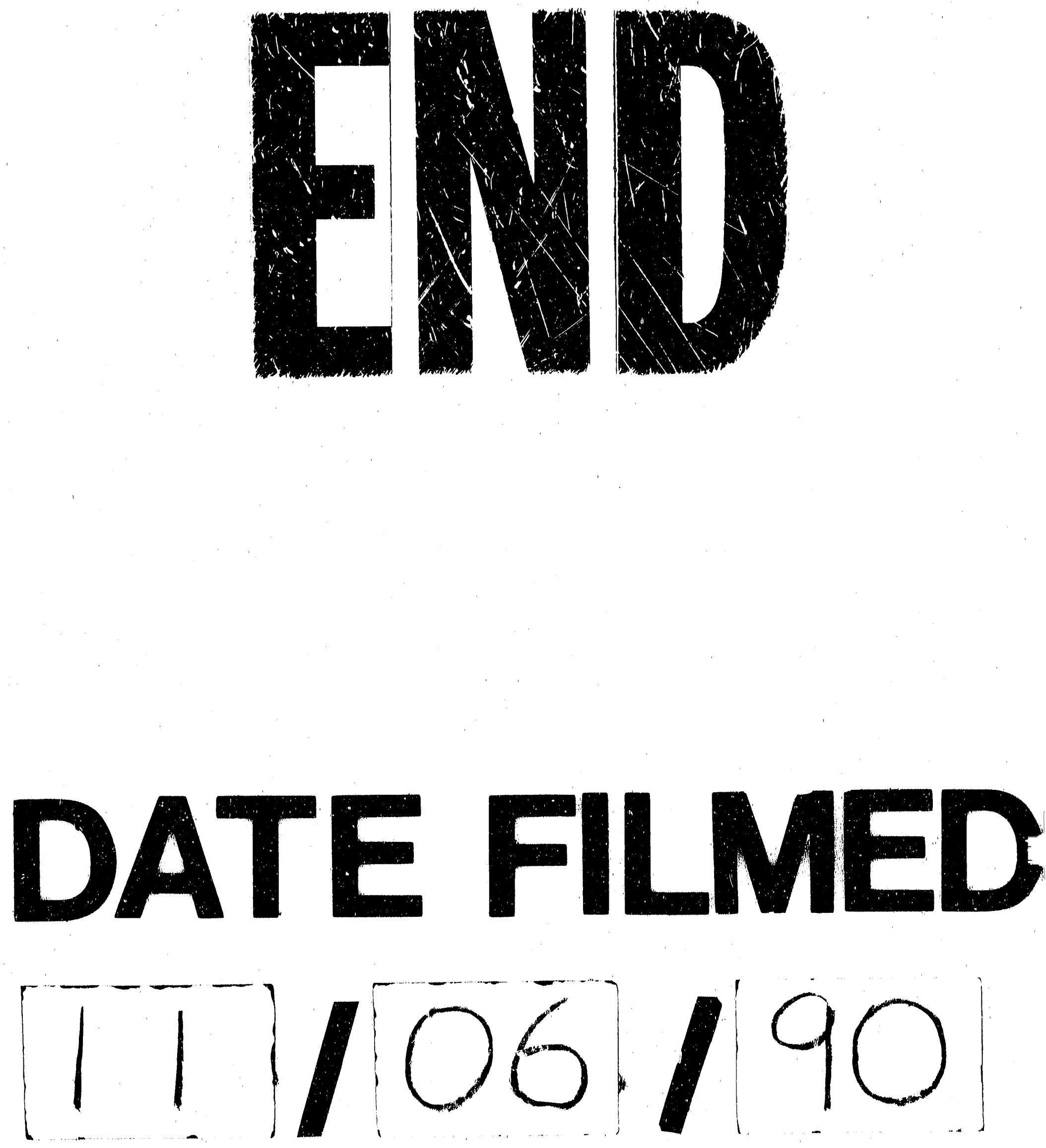


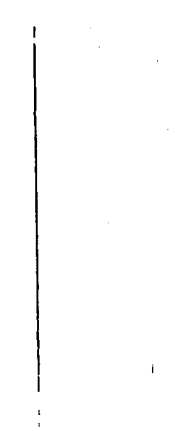

f 